\title{
Modeling the IFR-1 Experiment: A BISON Metallic Fuel Benchmark
}

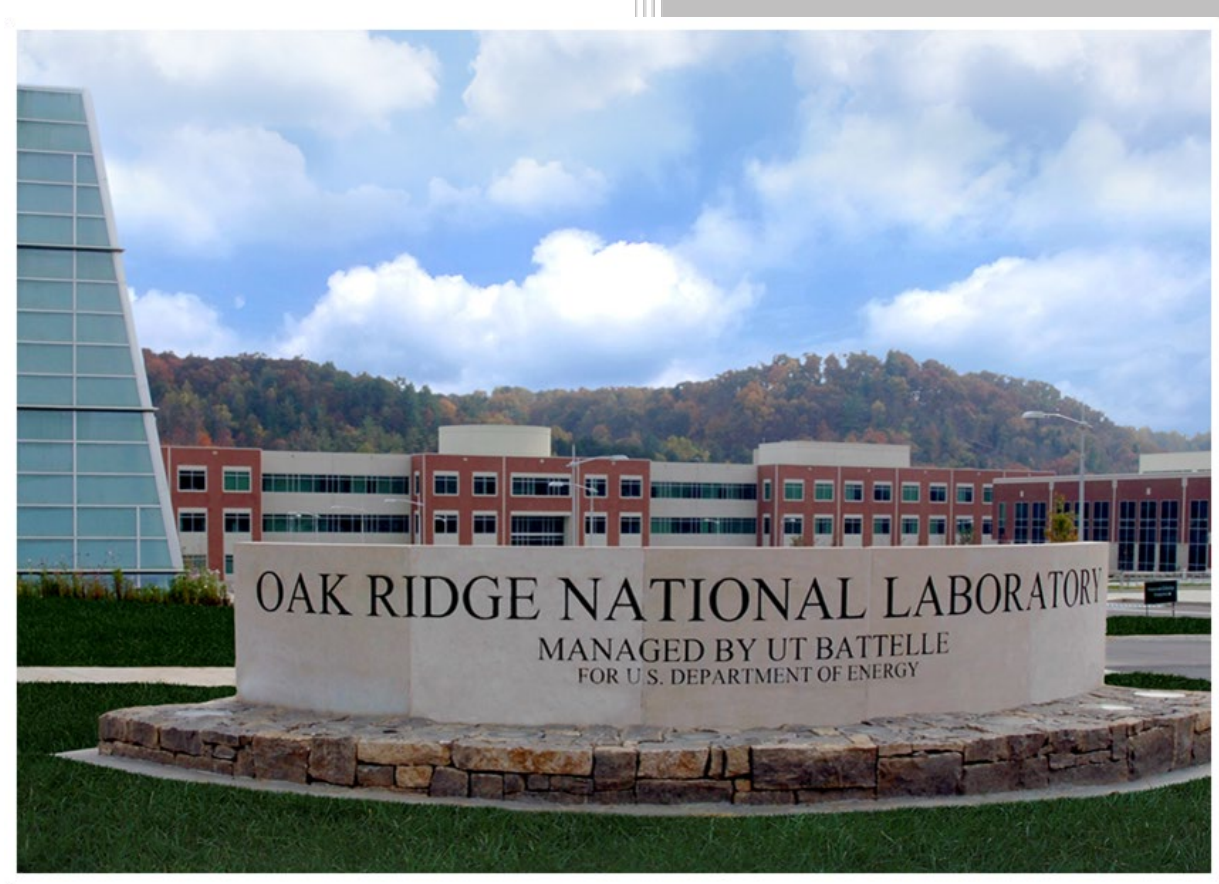

Approved for public release. Distribution is unlimited.

Kaylee M. Cunningham Jeffrey J. Powers

Robert A. Lefebvre

July 2019 


\section{DOCUMENT AVAILABILITY}

Reports produced after January 1, 1996, are generally available free via US Department of Energy (DOE) SciTech Connect.

Website www.osti.gov

Reports produced before January 1, 1996, may be purchased by members of the public from the following source:

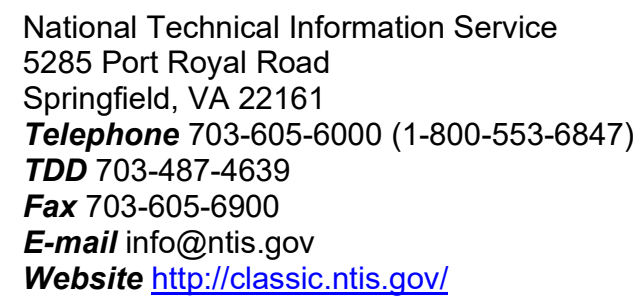

Reports are available to DOE employees, DOE contractors, Energy Technology Data Exchange representatives, and International Nuclear Information System representatives from the following source:

Office of Scientific and Technical Information

PO Box 62

Oak Ridge, TN 37831

Telephone 865-576-8401

Fax 865-576-5728

E-mail reports@osti.gov

Website http://www.osti.gov/contact.html

This report was prepared as an account of work sponsored by an agency of the United States Government. Neither the United States Government nor any agency thereof, nor any of their employees, makes any warranty, express or implied, or assumes any legal liability or responsibility for the accuracy, completeness, or usefulness of any information, apparatus, product, or process disclosed, or represents that its use would not infringe privately owned rights. Reference herein to any specific commercial product, process, or service by trade name, trademark, manufacturer, or otherwise, does not necessarily constitute or imply its endorsement, recommendation, or favoring by the United States Government or any agency thereof. The views and opinions of authors expressed herein do not necessarily state or reflect those of the United States Government or any agency thereof. 
Reactor Nuclear Systems Division

MODELING THE IFR-1 EXPERIMENT: A BISON METALLIC FUEL BENCHMARK

\author{
Kaylee M. Cunningham \\ Jeffrey J. Powers \\ Robert A. Lefebvre
}

July 2019

Prepared by

OAK RIDGE NATIONAL LABORATORY

Oak Ridge, TN 37831-6283

managed by

UT-BATTELLE, LLC

for the

US DEPARTMENT OF ENERGY

under contract DE-AC05-00OR22725 



\section{CONTENTS}

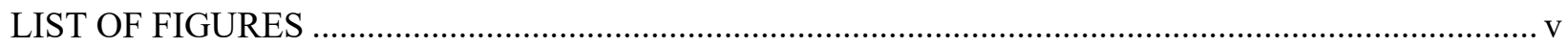

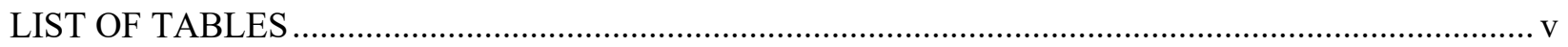

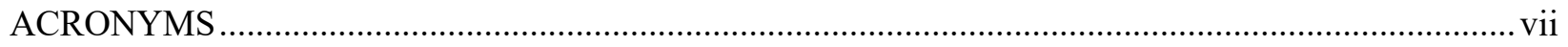

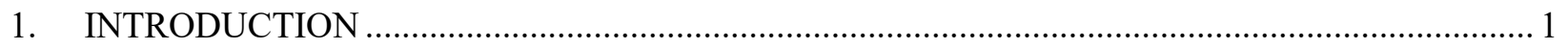

1.1 VERSATILE TEST REACTOR (VTR) .................................................................. 1

1.2 NUCLEAR ENERGY ADVANCED MODELING AND SIMULATION (NEAMS) .............. 1

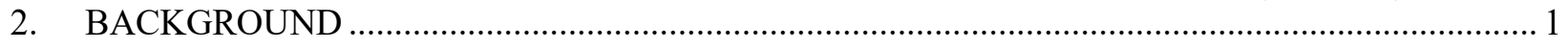

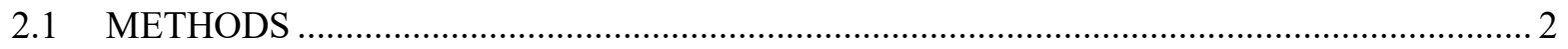

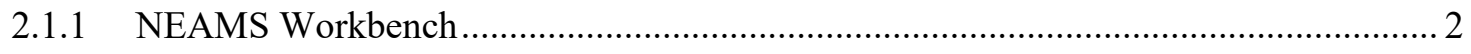

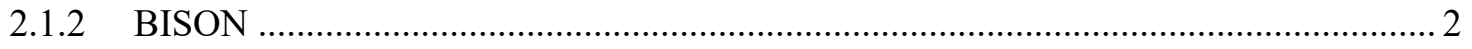

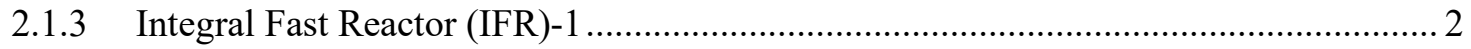

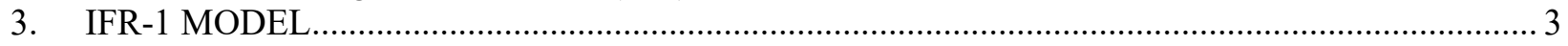

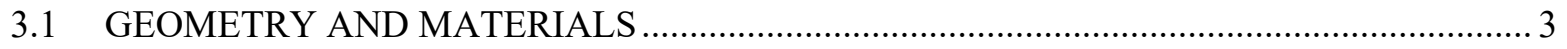

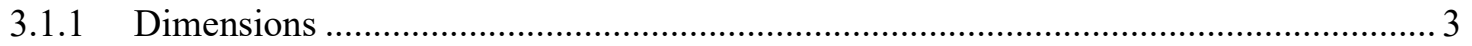

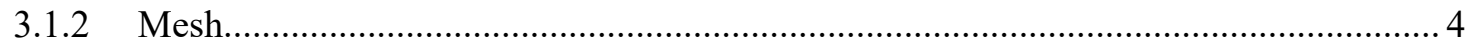

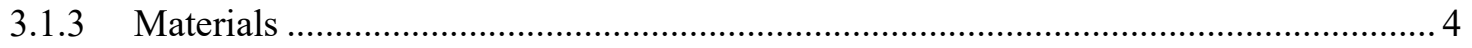

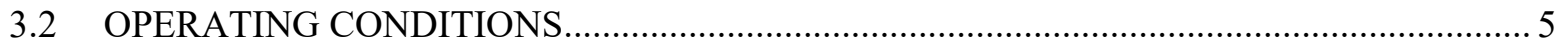

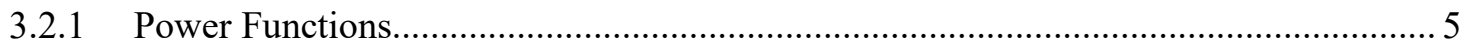

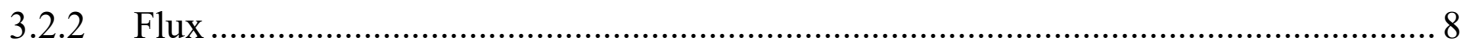

3.2.3 Coolant

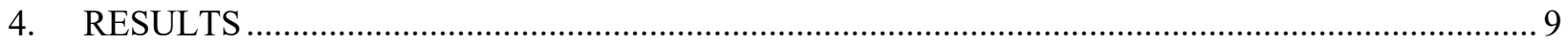

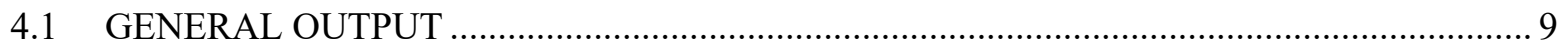

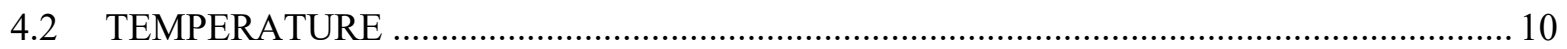

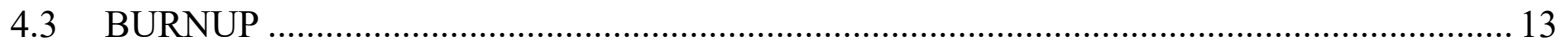

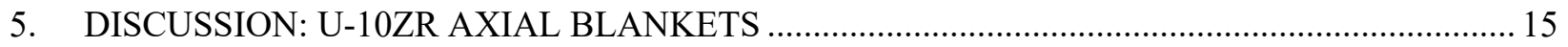

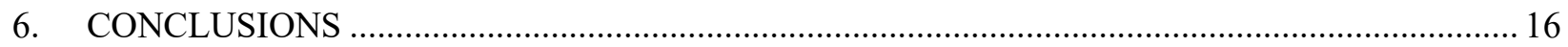

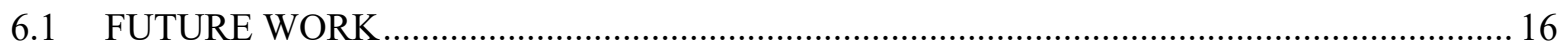

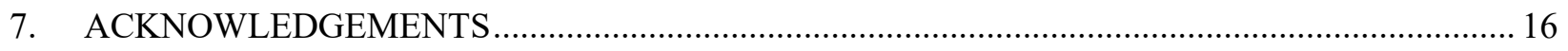

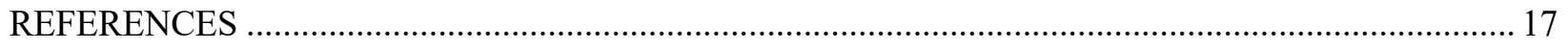

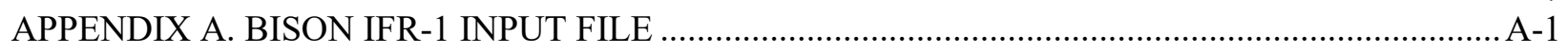





\section{LIST OF FIGURES}

Figure 1. Screenshot of mesh visualization (left), BISON input meshing parameters (center), and VisIt GUI (right) all within the NEAMS Workbench.

Figure 2. LHGR piecewise linear history reconstructed for IFR-1 U-20Pu-10Zr fuel pin over its operating lifetime.

Figure 3. Scatter plot of model's gap thickness (in micrometers) across average burnup (in \% FIMA).

Figure 4. BISON IFR-1 model temperature distribution visualization generated in NEAMS Workbench's VisIt GUI.

Figure 5. Scatter plot of IFR-1 model average fuel centerline temperature (in units of K) as a function of average burnup (in units of \%FIMA).

Figure 6. Connected scatter plot comparing cladding inner temperatures (in units of K) over time (in units of EFPD) between the BISON IFR-1 model and IFR-1 experimental values obtained from Reference [4].

Figure 7. Radial temperature distribution of the IFR-1 BISON model throughout the pin's life cycle.

Figure 8. BISON IFR-1 model overall burnup distribution visualization generated in NEAMS Workbench's VisIt GUI.

Figure 9. Comparison of Burnup Results Between IFR-1 Experiment (Reference [4], pages 84-87, Appendix A) and BISON Model.

\section{LIST OF TABLES}

Table 1. Dimensional Input Parameters with Sources ............................................................... 3

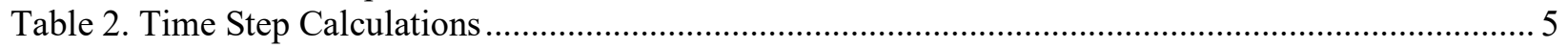

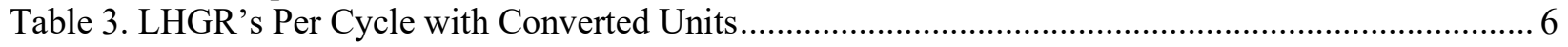

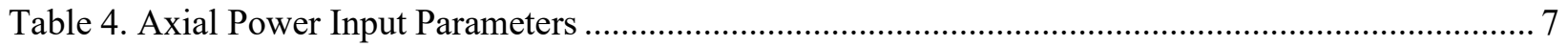

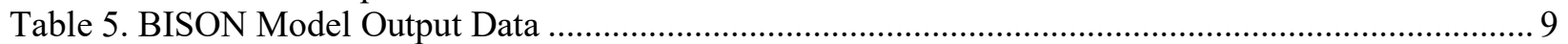

Table 6. IFR-1 Experiment and BISON Model Burnup Results and Relative Errors .............................. 14 



\section{ACRONYMS}

$\begin{array}{ll}\text { csv } & \text { comma separated variable } \\ \text { 1D } & \text { one-dimensional } \\ \text { 2D } & \text { two-dimensional } \\ \text { 2D-rz } & \text { 2D axially symmetric } \\ \text { 2D-r8 } & \text { 2D radial-azimuthal } \\ \text { BOC } & \text { beginning of cycle } \\ \text { CW } & \text { cold worked } \\ \text { DOE-NE } & \text { US Department of Energy Office of Nuclear Energy } \\ \text { DU } & \text { depleted uranium } \\ \text { EBR-II } & \text { Experimental Breeder Reactor-II } \\ \text { EFPD } & \text { effective full power day } \\ \text { EOC } & \text { end of cycle } \\ \text { FEM } & \text { finite element method } \\ \text { FFTF } & \text { Fast Flux Test Facility } \\ \text { FIMA } & \text { fissions per initial metal atom } \\ \text { GUI } & \text { graphical user interface } \\ \text { IFR } & \text { Integral Fast Reactor } \\ \text { LHGR } & \text { linear heat generation rate } \\ \text { MOOSE } & \text { Multiphysics Object Oriented Simulation Environment } \\ \text { NEAMS } & \text { Nuclear Energy Advanced Modeling and Simulation } \\ \text { NRC } & \text { US Nuclear Regulatory Commission } \\ \text { ORNL } & \text { Oak Ridge National Laboratory } \\ \text { PIE } & \text { post-irradiation examinations } \\ \text { VTR } & \text { Versatile Test Reactor }\end{array}$





\section{INTRODUCTION}

As the 1970s nuclear reactor fleet slowly begins the decommission process, the US Department of Energy Office of Nuclear Energy (DOE-NE) aims to stimulate and support the construction and implementation of new nuclear reactors across the country in hopes of continuing the generation of clean, reliable, resilient energy. As a result, various efforts have been introduced to accelerate this process, including the Versatile Test Reactor project (VTR) and the Nuclear Energy Advanced Modeling and Simulation (NEAMS) program.

\subsection{VERSATILE TEST REACTOR (VTR)}

The Versatile Test Reactor (VTR) is a new fast spectrum test reactor that is currently being developed in the United States under the direction of the US Department of Energy, Office of Nuclear Energy [1]. The VTR mission is to enable accelerated testing of advanced reactor fuels and materials required for advanced reactor technologies. This includes neutron irradiation capabilities which would support testing under alternate coolants including molten salt, lead/lead-bismuth eutectic mixture, gas, and sodium. The VTR aims at addressing most of the needs of the various stakeholders, primarily composed of advanced reactor developers, as well as a number of others interested parties. Design activities are underway at multiple national laboratories targeting a first criticality date by 2026, with General Electric-Hitachi joining the project to contribute to the VTR plant design. Current efforts are focused on all aspects of the VTR design.

The current proposed VTR concept is a 300 MWth sodium-cooled pool type reactor with metallic alloy fuel.

\subsection{NUCLEAR ENERGY ADVANCED MODELING AND SIMULATION (NEAMS)}

The NEAMS program is advancing modeling and simulation efforts focused on developing new tools to analyze and optimize the performance and reliability of existing and advanced nuclear power plants. NEAMS is developing computational tools that allow researchers to shed light on current problems and new ideas in unique ways that were previously considered impractical due to their excruciating detail. NEAMS can enhance understanding in areas ranging from changes in nuclear fuel materials to full-scale power plant operations [2].

The NEAMS mission is to develop, apply, deploy, and support state-of-the-art predictive modeling and simulation tools for design and analysis of current and future nuclear energy systems. This is accomplished by using computing architectures ranging from laptops to leadership-class computer facilities. The tools in the NEAMS ToolKit will enable transformative scientific discovery and insights otherwise not attainable or affordable and will accelerate the solutions to existing problems, as well as deployment of new designs for current and advanced reactors [2].

\section{BACKGROUND}

This report documents work performed at Oak Ridge National Laboratory (ORNL) to develop a twodimensional computational model of a U-19Pu-10Zr fuel pin from the IFR-1 metallic fuel experiment performed in the Fast Flux Test Facility (FFTF) in 1985. This model was created using the BISON fuel performance modeling code through a new platform developed by NEAMS known as Workbench. This model was generated to benchmark the BISON code for metallic fuel analysis. 


\subsection{METHODS}

BISON was set up remotely through NEAMS Workbench on a Windows machine and was used to generate this model.

\subsubsection{NEAMS Workbench}

The NEAMS Workbench is a software being developed to facilitate the transition from conventional to high-fidelity computational tools by providing a common user interface for model creation, review, execution, output review, and visualization for integrated codes [2].

The NEAMS Workbench can use common user input, including engineering-scale specifications, that are expanded into application-specific input requirements using customizable templates. The templating process enables multi-fidelity analysis of a system from a common set of input data. Additionally, the common user input processor can provide an enhanced alternative application input that provides additional conveniences over the native input, especially for legacy codes. The various integrated codes and application templates available in NEAMS Workbench broaden the user community and facilitate system analysis and design [2].

Ultimately, the NEAMS Workbench improves usability and streamlines the process of utilizing the BISON tool, locally and remotely. The software consists of an advanced text editor that incorporates input validation as well as auto-completion. Also available in the application's graphical user interface (GUI) data plotting to assist the user with analysis of input and output data. Through these capabilities the NEAMS Workbench provides a common analysis environment that aids in accelerating the user's adoption of advanced computational tools, such as BISON.

\subsubsection{BISON}

The BISON fuel performance code is a finite element method (FEM)-based software tool being developed by various organizations and led by the Idaho National Laboratory for DOE-NE. BISON is based on Idaho National Laboratory's Multiphysics Object Oriented Simulation Environment (MOOSE). The code can simulate a host of fuel and cladding compositions and geometries, including light-water reactor fuel rods, TRISO particle fuel, metallic rod, and plate fuel. Depending on the problem type and complexity level, varying dimensionality can be used in BISON, including one-dimensional (1D), 1.5D, 2D axially symmetric (2D-rz), 2D radial-azimuthal (2D-r $\mathrm{r}$ ), and 3D models. Visualizations can be created through third-party software such as Paraview or VisIt using the results stored in output Exodus files. BISON calculations include temperature- and burnup-dependent thermal properties, fission product swelling, thermal and irradiation creep, fission gas production and release, irradiation-induced swelling, and other phenomena [3].

For this model, BISON was used to analyze a U-19Pu-10Zr ternary metallic fuel alloy. This fuel composition is very similar to a proposed U-20Pu-10Zr driver fuel concept for VTR.

\subsubsection{Integral Fast Reactor (IFR)-1}

The IFR-1 experiment included irradiation of three fuel slug compositions: U-10Zr, U-8Pu-10Zr, and U19Pu-10Zr. All were clad in 20\% cold-worked (CW) D9. Of the 169 fuel pins in the IFR-1 experiment, 18 were U-19Pu-10Zr, 19 were U-8Pu-10Zr, and 132 were U-10Zr. The experiment was conducted in 1985 at the FFTF. The first of these irradiation tests performed at FFTF was IFR-1, which included 169 wirewrapped, sodium-bonded, full length ( $91.4 \mathrm{~cm}$ active fuel column height) metallic fuel elements. IFR-1 fuel pins contained axial blankets of depleted uranium (DU) U-10Zr that were $16.5 \mathrm{~cm}$ long and were 
situated above and below the main fuel column [6]. Post-irradiation examinations (PIE) demonstrated clear resemblance to short-pin (34.3 $\mathrm{cm}$ active fuel column height) experimentation of similar material composition that was performed at the Experimental Breeder Reactor-II (EBR-II) [4].

\section{IFR-1 MODEL}

ORNL stitched together information collected from various sources to construct a 2D-rz model of a generalized U-19Pu-10Zr fuel pin from the IFR-1 experiment.

\subsection{GEOMETRY AND MATERIALS}

The model was created according to the geometric input parameters specified in Table 1 below. The EBR-II x441 experiment model input file (x441.i), which is available in the BISON repository, was used as a starting template. A few IFR-1 input parameters have yet to be determined, but given the similarities between the IFR-1 experiment and the x441 EBR-II experiment, the values for missing IFR-1 parameters have been temporarily defined using values from the $\mathrm{x} 441 . \mathrm{i}$ input file as rough estimates.

\subsubsection{Dimensions}

Table 1 summarizes the dimensional input parameters used in the IFR-1 BISON model, along with the source of each parameter value and the line number on which that parameter can be found in the current IFR-1 BISON model.

Table 1. Dimensional Input Parameters with Sources

\begin{tabular}{|l|c|c|c|}
\hline \multicolumn{1}{|c|}{ Parameter } & Value & Source & $\begin{array}{c}\text { Input file line } \\
\text { number }\end{array}$ \\
\hline Slug outer radius & $2.490 \mathrm{~mm}$ & {$[5, \text { pg. } 47]^{1}$} & 31 \\
\hline Initial Na bond gap thickness & $0.380 \mathrm{~mm}$ & derived & 34 \\
\hline Cladding thickness & $0.560 \mathrm{~mm}$ & {$[5$, pg. 47$]$} & $30^{2}$ \\
\hline Rod diameter & $6.86 \mathrm{~mm}$ & {$[5$, pg. 47$]$} & 517 \\
\hline Rod pitch & $8.230 \mathrm{~mm}$ & {$[5, \text { pg. } 47]^{3}$} & 518 \\
\hline Fuel slug height & $91.40 \mathrm{~cm}$ & {$[5$, pg. 47$]$} & 32 \\
\hline Plenum height & $106.2 \mathrm{~cm}$ & {$[6$, pg. 125] } & 33 \\
\hline End-plug thickness & $2.240 \mathrm{~mm}$ & {$[\mathrm{x} 441 . \mathrm{i}]$} & 35 \\
\hline Gap between slug bottom and end-plug top & $0.310 \mathrm{~mm}$ & {$[\mathrm{x} 441 . \mathrm{i}]$} & 36 \\
\hline
\end{tabular}

Parameters such as rod diameter and rod pitch were not explicitly defined in the literature; in such cases, footnotes are included herein to provide further detail on how these values were derived from source(s) cited.

\footnotetext{
${ }^{1}$ The radius is not explicitly stated; the reference provides the slug's outer diameter, which was used to derive the radius value listed.

${ }^{2}$ All line number references in the text of this report refer to line numbers in Appendix A.

${ }^{3}$ Pitch is not explicitly stated; however, the source defines the outer diameters of the pin and wire. Reference [1] provides a photo (page 111) of the fuel bundle illustrating a single wire between neighboring rods, with neighboring wires offset axially. Therefore, pitch equates to the sum of the wire's outer diameter to the pin's outer diameter. These values were added to obtain rod pitch.
} 


\subsubsection{Mesh}

A customized smeared pellet mesh was generated through the BISON input file using a QUAD8 element type from libMesh. In the mesh, 6 fuel elements were defined in the radial direction, while 260 were defined in the axial direction. Cladding consisted of 4 elements defined in the radial direction and 260 in the axial direction, along with 3 radial elements in the upper end plug and 1 axial element in the lower end plug. Future work should perform, and document, a mesh optimization study to more explicitly balance accuracy and calculation runtime. A centroid partitioner was specified with a sort in the y direction. Patch size, or the number of nodes considered in the NearestNode neighborhood, was set to 50, and the update strategy was set to automatic (see Figure 1).

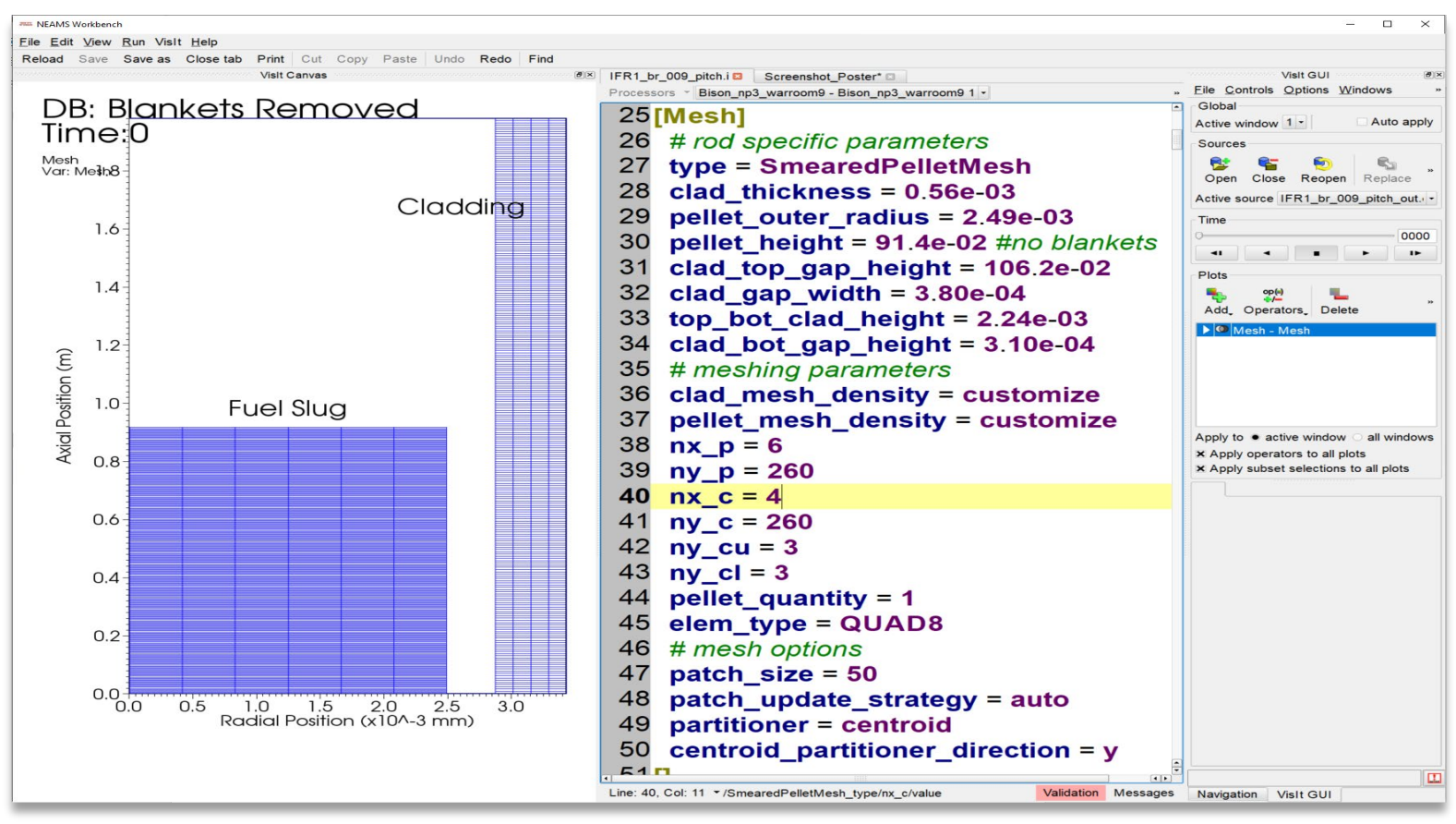

Figure 1. Screenshot of mesh visualization (left), BISON input meshing parameters (center), and VisIt graphical user interface (GUI) (right) all within the NEAMS Workbench.

\subsubsection{Materials}

The materials used in the IFR-1 experiment included a U-19-Pu-10Zr ternary alloy fuel clad in $20 \% \mathrm{CW}$ D9. To replicate this, the molar fractions within the input file were set to $\mathrm{x}_{-} \mathrm{Pu}=0.19$ and $\mathrm{x} \_\mathrm{Zr}=0.10$ in four different places (lines 531-532, 538-539, 546-547, 587-588). Modeling the D9 cladding proved difficult because D9 material models are not currently included in BISON. HT9 cladding materials were used for now, but IFR-1 model should be updated when D9 material models are added to BISON.

As a simplification, the DU U-10Zr axial blankets were not included in this initial model. Limitations in BISON's internal mesh generation script prevent modeling two different fuel slug types in a single mesh; this simplification of ignoring the U-10Zr axial blankets therefore avoids the need to use external mesh generation resources. As a result, this modeling approximation ignores mechanical and thermal impacts of the blankets by assuming that all power production occurs in the main fuel column. This should be conservative for thermal analysis due to concentrating power production into a smaller region. The mechanical impacts of this approximation should be small and are considered acceptable for this baseline model [7]. This document therefore primarily focuses on this initial baseline model, with no axial blankets. However, a study performed comparing an approximation to simulating the blankets will be 
explored in Section 5. Additional options are also being investigated to explicitly model the axial blankets, including possible use of mesh modifiers in BISON or external mesh generation tools.

\subsection{OPERATING CONDITIONS}

Determining operating conditions for the BISON model input file required a detailed search through the literature, as well as drawing from the information recorded to indirectly calculate required parameter values that were not stated explicitly. In particular, calculations were performed to determine power functions, time steps, and flux, while coolant parameters were mostly assembled from various sources within the literature.

\subsubsection{Power Functions}

BISON input requires that certain functions be defined with corresponding time steps: specifically linear heat generation rate (LHGR) and axial power peaking factors. Obtaining input data for time, LHGR, and axial power required literature examination, as well as subsequent calculations.

\subsubsection{Time}

BISON requires that power function data have respective corresponding time steps defined in a list as the $x$ variable for linear functions (lines 158,165 , and 172$)^{4}$. In line 188 , because axial power is a bilinear function, time is the $y$ variable.

Appendix A, "Detailed Pin and Assembly Composition, Flow and Power Characteristics," in Porter and Tsai's Full-length Metallic Fast Reactor Fuel Pin Test in FFTF [4], includes a table detailing the time cycles for IFR-1. Effective full power days (EFPDs) are listed for each cycle. Page 67 in the same document [4] lists the cycles as 9A, 9B, 9C, 10A, 10A-2, and 10B. However, page 65 includes an inconsistency in cycle names, listing them as: 9A-1, 9A-2, 9B, 10A-1, 10A-2, 10A-3, 10A-4, and 10B. Consequently, cycle 9A-2 from this table (page 65) was assumed to be 9B; 9B was assumed to be 9C; $10 \mathrm{~A}-1$ to be $10 \mathrm{~A} ; 10 \mathrm{~A}-2,10 \mathrm{~A}-3$, and 10A-4 were added together and assumed to be $10 \mathrm{~A}-2$, and $10 \mathrm{~B}$ remained 10B. These assumptions were made based on the remainder of the Appendix A [4] cycle references and notes included with the table. After the specified cycle durations (in EFPDs) were summed, each cycle's total duration (in EFPDs) was multiplied by 86,400 to convert them to seconds $(3,600 \mathrm{~s} / \mathrm{hr} \times 24 \mathrm{hr}=86,400 \mathrm{~s})$. Cumulative duration was then calculated for each point in time. One hour $(3,600 \mathrm{~s})$ was added between cycles to separate time steps and to smooth calculations within BISON. This process resulted in the list of time steps provided in Table 2.

Table 2. Time Step Calculations

\begin{tabular}{|l|c|r|r|}
\hline \multicolumn{1}{|c|}{ Cycle } & Time per cycle (EFPDs) & \multicolumn{1}{c|}{ Calculation } & \multicolumn{1}{c|}{ Time (s) } \\
\hline 0 & N/A & $0=$ & 0 \\
\hline 9A BOC & N/A & $(29.4 \times 86400)+3600=$ & $2,543,760$ \\
\hline 9A EOC & 29.4 & $2543760+3600=$ & $2,547,360$ \\
\hline 9B BOC & N/A & $(108.3 \times 86400)+2547360=$ & $11,904,480$ \\
\hline 9B EOC & 108.3 & $11904480+3600=$ & $11,908,080$ \\
\hline 9C BOC & N/A & $(97.7 \times 86400)+11908080=$ & $20,349,360$ \\
\hline 9C EOC & 97.7 & $20349360+3600=$ & $20,352,960$ \\
\hline 10A BOC & N/A & &
\end{tabular}

\footnotetext{
${ }^{4}$ For all line number references, see Appendix A.
} 


\begin{tabular}{|l|c|r|l|}
\hline $10 \mathrm{~A} \mathrm{EOC}$ & 66.3 & $(66.3 \times 86400)+20352960=$ & $26,081,280$ \\
\hline $10 \mathrm{~A}-2 \mathrm{BOC}$ & $\mathrm{N} / \mathrm{A}$ & $26081280+3600=$ & $26,084,880$ \\
\hline $10 \mathrm{~A}-2 \mathrm{EOC}$ & 85.5 & $(85.5 \times 86400)+26084880=$ & $33,472,080$ \\
\hline $10 \mathrm{~B}$ BOC & N/A & $33472080+3600=$ & $33,475,680$ \\
\hline $10 \mathrm{~B}$ EOC & 126.7 & $(126.7 \times 86400)+33475680=$ & $44,422,560$ \\
\hline
\end{tabular}

\subsubsection{LHGR}

For BISON to determine LHGR ( [ . / power_history] on line 156), $x$ and $y$ variables must be defined. In this case, $x$ is the time in seconds mentioned previously, and $y$ is LHGR in units of W/m.

To stitch together a plot of the two variables, information was again obtained from Appendix A of Porter and Tsai's 2011 document [4]. In particular, Table 1 on page 93 contains a list of peak axial pin powers for 181\#\#\# pins as determined by Westinghouse. Pin 181193, (listed as 193 in the pin column) is the only U-19Pu-10Zr pin destructively examined [4, pg. 1]; the beginning of cycle (BOC) and end of cycle (EOC) LHGRs are listed in units of $\mathrm{kW} / \mathrm{ft}$ for six FFTF operating cycles. These values were recorded in a spreadsheet. The BOC and EOC LHGRs for each cycle were then converted from $\mathrm{kW} / \mathrm{ft}$ (given units) to $\mathrm{W} / \mathrm{m}$ (required units for BISON). Table 3 below summarizes this information.

Table 3. LHGR's Per Cycle with Converted Units

\begin{tabular}{|l|l|l|l|l|c|c|}
\hline \multicolumn{1}{|c|}{ Cycle } & 9A & 9B & 9C & 10A & 10A-2 & 10B \\
\hline BOC $(\mathrm{kW} / \mathrm{ft})$ & 13.94 & 12.33 & 12.14 & 10.86 & 10.06 & 9.80 \\
\hline EOC $(\mathrm{kW} / \mathrm{ft})$ & 13.14 & 11.65 & 11.66 & $10.86^{5}$ & 9.14 & 9.66 \\
\hline BOC $(\mathrm{kW} / \mathrm{m})$ & 45.7232 & 40.4424 & 39.8192 & 35.6208 & 32.9968 & 32.1440 \\
\hline EOC $(\mathrm{kW} / \mathrm{m})$ & 43.0992 & 38.2120 & 38.2448 & 35.6208 & 29.9792 & 31.6848 \\
\hline
\end{tabular}

The LHGR values were listed chronologically for the y input in [ . / power_history] (line 160). Figure 2 shows the time-dependent LHGR history as reconstructed and used in BISON for this pin, with time converted to days to enhance clarity and understanding.

\footnotetext{
${ }^{5}$ No EOC LHGR was listed, so 10.86 was used for BOC and EOC.
} 


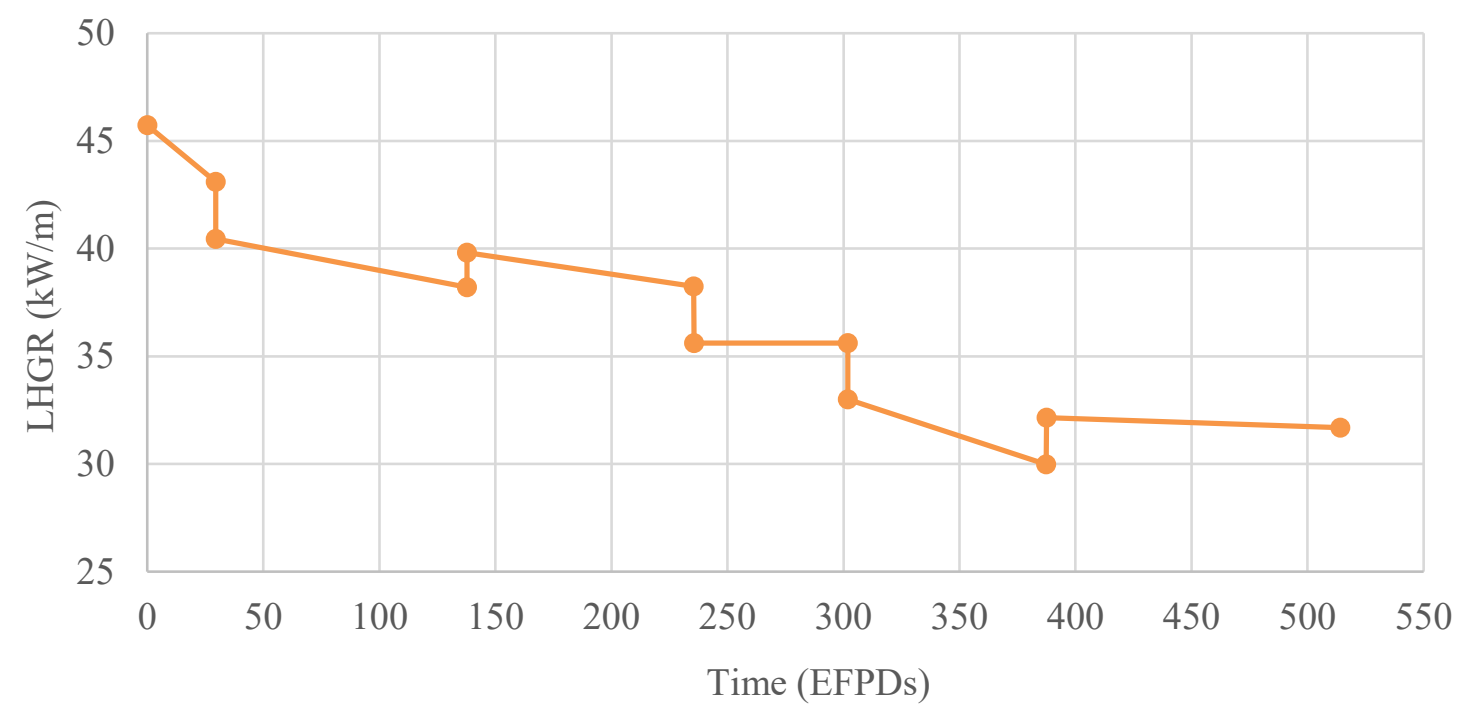

Figure 2. LHGR piecewise linear history reconstructed for IFR-1 U-20Pu-10Zr fuel pin over its operating lifetime.

\subsubsection{Axial Power}

Axial power distribution is required for the BISON input ([ . / axial_peaking_factors] line 177) and was also determined from Appendix A in Porter and Tsai's 2011 document [4]. On page 101, a figure displays local power and temperature as a function of axial position for IFR-1 pin 181193. Relative axial position is indicated as $x / L$ in that figure and in this work, where $x$ is the local axial height, and $L$ is the total active fuel height of the pin. Focusing on the axial power curve, a web-based data extraction tool was used to pull points from the plot and export them into a comma-separated variable (.csv) file that was opened in a spreadsheet.

All positions in $\mathrm{x} / \mathrm{L}$ were then multiplied by $0.914 \mathrm{~m}$, which was the length of the active fuel column, to covert to axial position in meters; these products were listed as the $x$ variable (line 179) in [./axial_peaking_factors]. The same time steps (see Section 3.2.1.1) were listed to define the $y$ variable (line 188), which is time. All powers extracted were then converted from units of $\mathrm{kW} / \mathrm{ft}$ to $\mathrm{kW} / \mathrm{m}$. These values were averaged to calculate a pin-average LHGR. Each individual local axial power was divided by the calculated pin-average LHGR to produce a height-dependent local relative power. The resulting list of relative powers was entered in a repeating list for the $\mathrm{z}$ variable (line 192). All of this axial power information is summarized in Table 4.

Table 4. Axial Power Input Parameters

\begin{tabular}{|c|c|}
\hline $\mathbf{x} / \mathbf{L}$ & Power $\mathbf{( k W / m )}$ \\
\hline 0.0009 & 16.862571 \\
\hline 0.00763 & 19.431812 \\
\hline 0.0137 & 22.061049 \\
\hline 0.05058 & 25.219242 \\
\hline 0.10088 & 29.868338 \\
\hline 0.14982 & 33.381704 \\
\hline 0.20077 & 37.073859 \\
\hline 0.25038 & 40.347839 \\
\hline
\end{tabular}




\begin{tabular}{|c|c|}
\hline 0.30065 & 42.664878 \\
\hline 0.35023 & 44.025375 \\
\hline 0.40047 & 44.727912 \\
\hline 0.44066 & 44.895286 \\
\hline 0.45071 & 44.892282 \\
\hline 0.50027 & 44.279499 \\
\hline 0.55049 & 43.307739 \\
\hline 0.6007 & 41.498829 \\
\hline 0.6509 & 38.972363 \\
\hline 0.70042 & 35.848134 \\
\hline 0.7506 & 32.125741 \\
\hline 0.80012 & 28.463344 \\
\hline 0.85096 & 24.082991 \\
\hline 0.90047 & 19.882427 \\
\hline 0.95064 & 15.382682 \\
\hline 0.96937 & 13.403795 \\
\hline 0.97938 & 10.47077 \\
\hline 0.98605 & 8.1367096 \\
\hline 0.99204 & 5.6832568 \\
\hline 0.99938 & 3.647978 \\
\hline
\end{tabular}

\subsubsection{Flux}

BISON requires a flux factor, which is a ratio of flux to power in units of $\frac{\mathrm{n} / \mathrm{cm}^{2}-s}{\mathrm{w} / \mathrm{m}}$. Determining this fast flux factor for the [./fast_flux] block within the materials block (line 620) required calculations based on values Porter and Tsai's 2011 document [4]. On page 2 [4], the EOL fast fluence of IFR-1 was defined as $15.6 \times 10^{22} \mathrm{n} / \mathrm{cm}^{2}$. This EOL fast fluence was divided by the previously calculated EOL time (see Section 3.2.1.1, Table 2) to calculate an average fast flux of $3.5 \times 10^{15} \mathrm{n} / \mathrm{cm}^{2}$-s, as shown in Eq. (1) below.

$$
\frac{15.6 \times 10^{22} \frac{\mathrm{n}}{\mathrm{cm}^{2}}}{44422560 \mathrm{~s}}=3.5 \times 10^{15} \frac{\mathrm{n}}{\mathrm{cm}^{2}-\mathrm{s}}
$$

The lifetime average LHGR, an average of all BOL and EOL LHGR values listed in Table 3, was calculated to be approximately $37,000 \mathrm{~W} / \mathrm{m}$. The lifetime-average fast flux $\left(3.5 \times 10^{15} \mathrm{n} / \mathrm{cm}^{2}-\mathrm{s}\right)$ was divided by this lifetime-average LHGR $(37,000 \mathrm{~W} / \mathrm{m})$ to produce a flux factor of $9.5 \times 10^{10} \frac{\mathrm{n} / \mathrm{cm}^{2}-\mathrm{s}}{\mathrm{W} / \mathrm{m}}$. As shown in $\mathrm{Eq}(2)$, this was converted from $\mathrm{cm}^{2}$ to $\mathrm{m}^{2}$ to calculate the final flux factor used for the BISON input of $9.5 \times 10^{14} \frac{\mathrm{n} / \mathrm{m}^{2}-\mathrm{s}}{\mathrm{W} / \mathrm{m}}$.

$$
\begin{gathered}
\frac{3.5 \times 10^{15} \frac{\mathrm{n}}{\mathrm{cm}^{2}-\mathrm{s}}}{37000 \mathrm{~W} / \mathrm{m}}=9.5 \times 10^{10} \frac{\mathrm{n} / \mathrm{cm}^{2}-\mathrm{s}}{\mathrm{W} / \mathrm{m}} \times 10^{4} \frac{\mathrm{cm}^{2}}{\mathrm{~m}^{2}} \\
=9.5 \times 10^{14} \frac{\mathrm{n} / \mathrm{m}^{2}-\mathrm{s}}{\mathrm{W} / \mathrm{m}}
\end{gathered}
$$




\subsubsection{Coolant}

Coolant parameters were mostly determined from the literature. The coolant temperature ramp required for the functions block_- . / coolant_temp_ramp] line 170-was defined as a constant temperature at each time step. That temperature was obtained from the literature [8] as $360{ }^{\circ} \mathrm{C}$ and converted to Kelvin $(633 \mathrm{~K})$. This was input for the $y$ values, except for the first and last time steps in line 167 . The first time step is set at room temperature $(298 \mathrm{~K})$, and the last is a decrease of roughly $50 \%$ in temperature $(350 \mathrm{~K})$.

However, some parameters have not yet been found. Specifically, values for the coolant pressure ramp function block ([ . / coolant_press_ramp] line 163) could not be determined. Given the similarities between EBR-II and FFTF, the coolant pressure value from the $\mathrm{x} 441 \mathrm{BISON}$ input $(0.151 \mathrm{MPa})$ is used in this IFR-1 model for now should be sufficient. The inlet mass flux (in units of $\frac{\mathrm{kg}}{\mathrm{m}^{2}-\mathrm{s}}$ ) required for the coolant channel block in BISON ( [ . / convective_clad_surface] line 515) has also been unobtainable thus far. For now, the value from the $\mathrm{x} 441 \mathrm{BISON}$ model $\left(5261.5 \frac{\mathrm{kg}}{\mathrm{m}^{2}-\mathrm{s}}\right)$ is used in this IFR1 model, although this is almost certainly at least slightly inaccurate. Temperature values, especially for cladding, may be consequently skewed. As soon as a more accurate inlet mass flux can be calculated or obtained, the model must be updated and adjusted accordingly.

\section{RESULTS}

Numerous simulations were performed to generate visualizations of various parameters of interest and to develop detailed analyses comparing documented IFR-1 experimental results to the results from this BISON model. Specifically, burnup and temperature were compared directly to IFR-1 experimental data.

\subsection{GENERAL OUTPUT}

Table 5 below summarizes the BISON model's most essential parameters at EOL that are of interest to the VTR project and potentially to the general nuclear community.

Table 5. BISON Model Output Data

\begin{tabular}{|l|c|}
\hline \multicolumn{1}{|c|}{ Parameter } & Value \\
\hline Peak fuel temperature (at 138 d) & $1,160 \mathrm{~K}$ \\
\hline Peak cladding temperature (at 1 hr) & $955 \mathrm{~K}$ \\
\hline Maximum average fuel surface temperature during operation (at 1 hr) & $867 \mathrm{~K}$ \\
\hline Maximum average inner cladding temperature during operation $($ at $1 \mathrm{hr})$ & $897 \mathrm{~K}$ \\
\hline EOL average burnup & $6.5 \%$ \\
\hline EOL peak burnup & $8.7 \%$ \\
\hline EOL plenum pressure & $3.9 \mathrm{MPa}$ \\
\hline EOL maximum hoop stress & $63 \mathrm{MPa}$ \\
\hline EOL maximum cladding creep strain & $5.33 \times 10-4$ \\
\hline EOL fission gas release & $92.3 \%$ \\
\hline EOL maximum cumulative damage fraction & $8.60 \times 10^{-4}$ \\
\hline
\end{tabular}

The maximum hoop stress of approximately $63 \mathrm{MPa}$ occurred $0.51 \mathrm{~m}$ from the bottom of the active fuel column $(\mathrm{x} / \mathrm{L}=0.6)$. The peak burnup of $8.7 \%$ fissions per initial metal atom (FIMA) was achieved $0.42 \mathrm{~m}$ above the bottom of the active fuel column $(\mathrm{x} / \mathrm{L}=0.5)[7]$. Gap thickness, as illustrated in Figure 3, 
decreases as burnup progresses until fuel and cladding come into contact. Results for this model indicate gap closure (fuel-cladding contact) occurs at roughly $6.6 \%$ average burnup; however, past experiments indicate the gap should close sooner, so this requires further investigation.

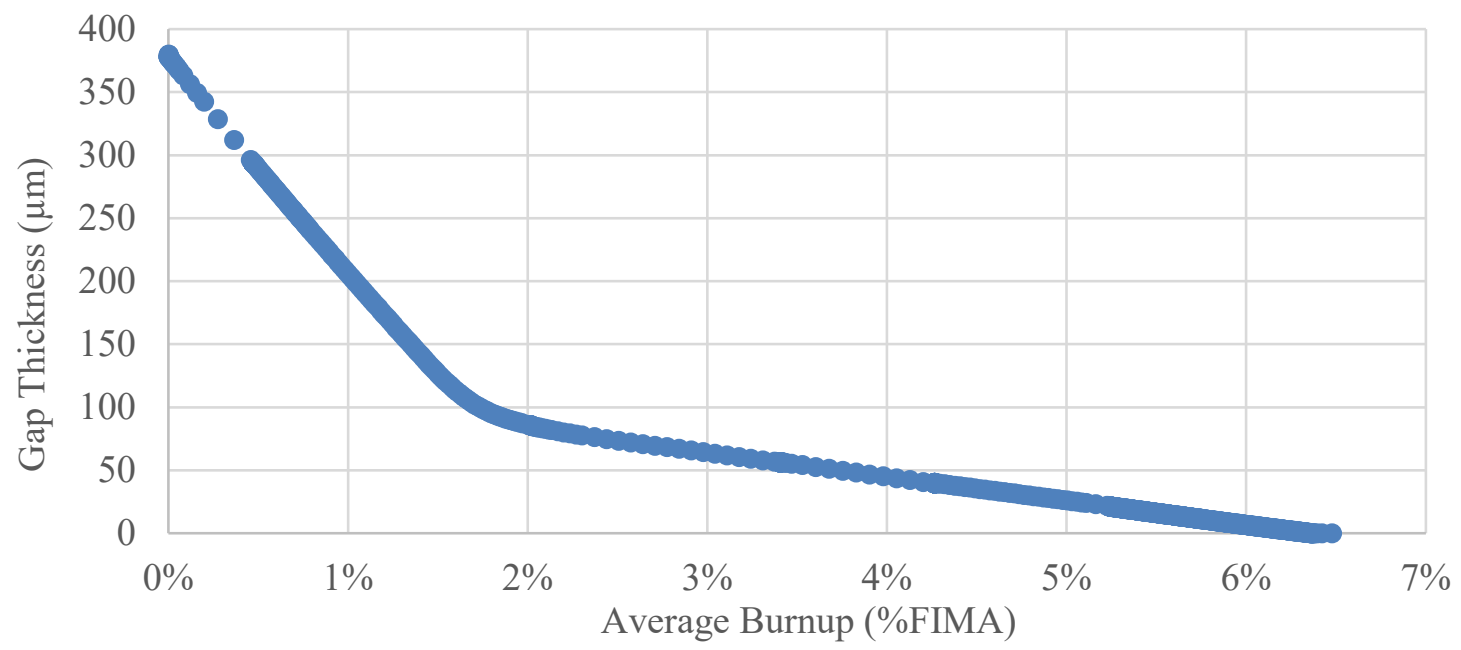

Figure 3. Scatter plot of model's gap thickness (in micrometers) across average burnup (in \% FIMA).

Collectively, these output values produced by the IFR-1 BISON model generally meet the qualitative behavior expectations.

\subsection{TEMPERATURE}

Temperature was expected to be slightly skewed due to the incorrect inlet mass flux value used in the input file. Generally, this was demonstrated in the following results. The overall temperature distribution (Figure 4) and the average fuel centerline temperature (Figure 5) appear to be qualitatively reasonable. Figure 4 shows the average fuel centerline temperature peaks in the middle of the fuel slightly above the center, as expected, and then decreases radially and axially as heat is conducted outward and fission rates also decrease. The cladding temperature distribution follows the coolant temperature distribution axially, with lower temperatures near the inlet at the bottom and higher temperatures near the outlet at the top, while also exhibiting the expected slightly higher temperature at cladding inner surface that decreases radially outward through the cladding. 


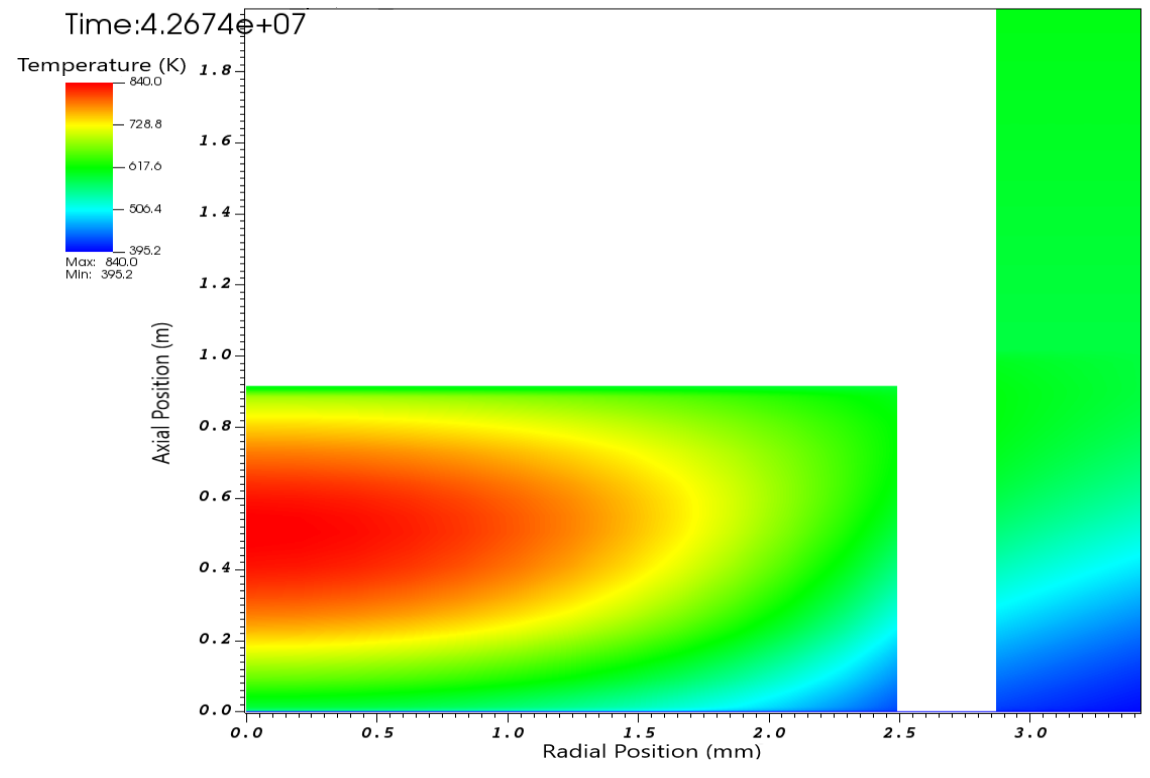

Figure 4. BISON IFR-1 model temperature distribution visualization generated in NEAMS Workbench's VisIt GUI.

The average fuel centerline temperature illustrated in Figure 5 shows trends demonstrating two main effects overlaid on top of each other: time-dependent variations in rod-average LHGR as well as burnupdependent changes in fuel thermal conductivity. Time-dependent changes in the rod-average LHGR directly impact the fuel temperature, as portrayed by the discontinuities in Figure 5. They occur when the power history curve in Figure 2 shows the same discontinuities. At the same time, the overall shape of the results in Figure 5 follow the burnup-dependent evolution of fuel thermal conductivity during irradiation of UPuZr metal fuel; the fuel thermal conductivity starts out highest in the fresh fuel, decreases during irradiation until hitting a minimum fuel thermal conductivity around $2 \%$ FIMA which is when fuel temperature peaks, and then slightly recovers some thermal conductivity as burnup progresses to around $5 \%$ FIMA. 


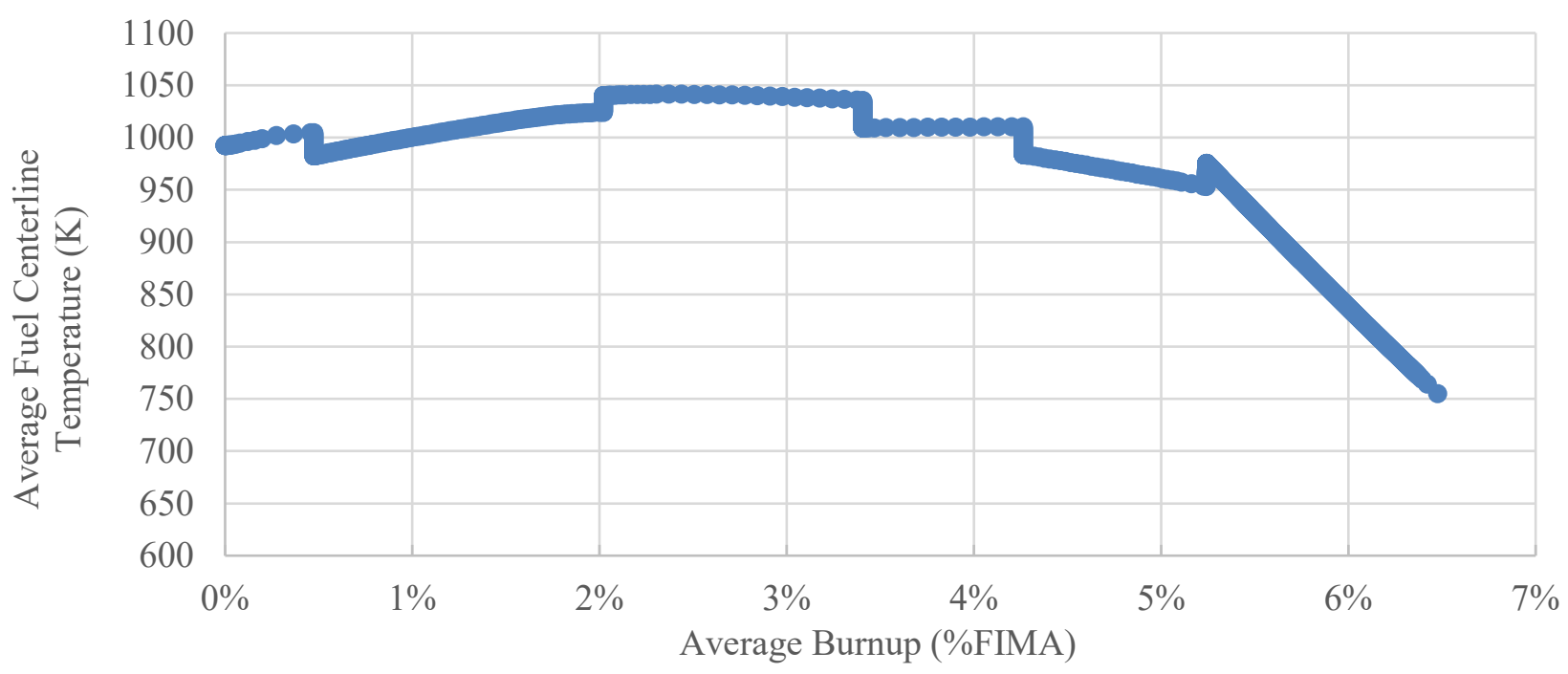

Figure 5. Scatter plot of IFR-1 model average fuel centerline temperature (K) as a function of average burnup (\%FIMA).

The cladding's inner temperature (Figure 6) illustrates the expected error; the model results generally follow the same behavioral trends as the experimental data, but they are approximately $25 \mathrm{~K}$ higher. This indicates a possible consistent bias in the model which could be resolved with improved coolant inlet conditions.

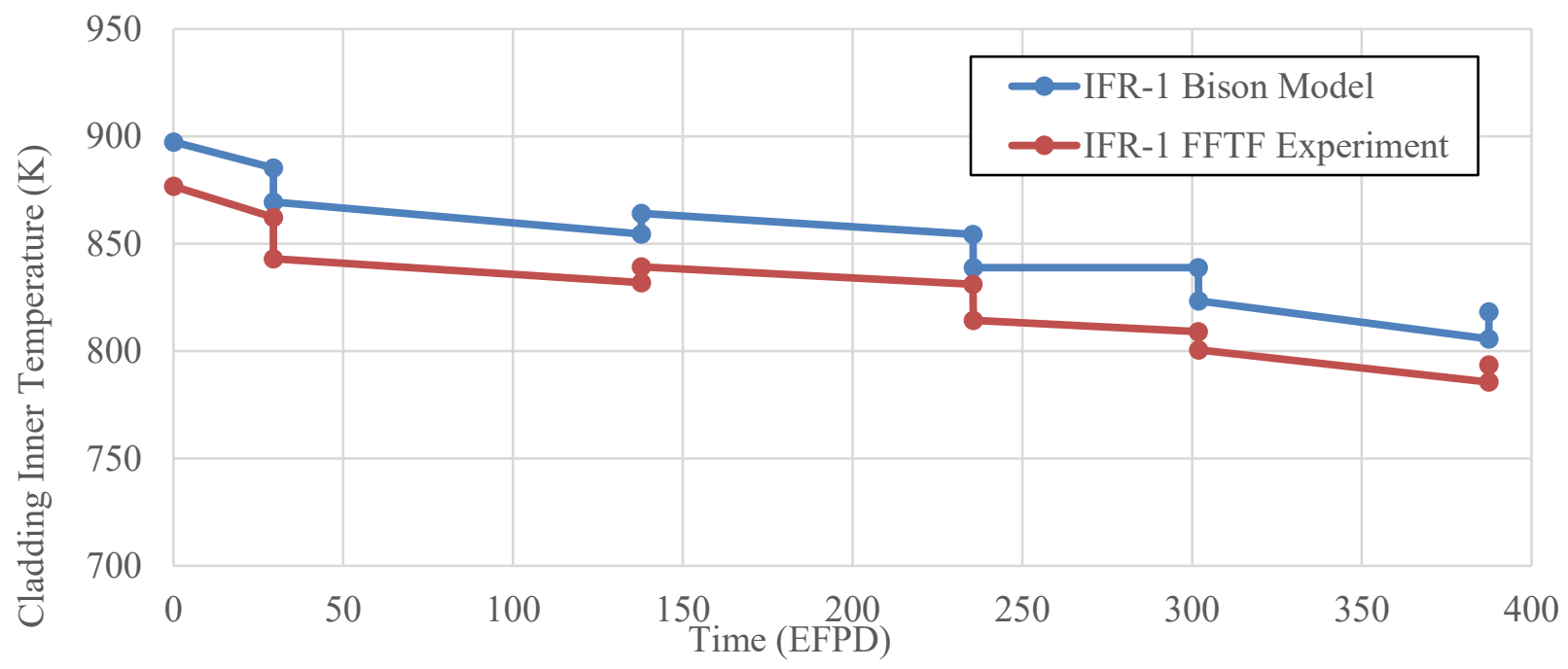

Figure 6. Connected scatter plot comparing cladding inner temperatures (K) over time (EFPDs) between the BISON IFR-1 model and IFR-1 experimental values obtained from Porter and Tsai, 2011 [4] ${ }^{6}$.

The EOL average fuel surface temperature produced was $563 \mathrm{~K}$, while the EOL average inner cladding temperature was $580 \mathrm{~K}$. This created initial concern because the cladding temperature should be lower than the fuel temperature. However, the radial temperature distributions shown in Figure 7 across the axial center of the pin $(\mathrm{x} / \mathrm{L}=0.5)$ for several points in time show reasonable radial temperature distributions. The EOL average inner cladding temperature being higher than the EOL average fuel

${ }^{6}$ The experimental values from Porter and Tsai [4] are found in the figure on page 100. The temperatures used were converted from Celsius to Kelvin by adding 273 to each value. 
surface temperature is therefore most likely a result of the approaches used to calculate those average values; the cladding is taller than the fuel height, so low temperature conditions near the coolant inlet matter less in the cladding than in the fuel. When comparing fuel and cladding average temperatures in the future, it would be best to average them over the same axial region (active fuel length) to enable direct comparisons, in addition to calculating a true (full-height) axially-averaged cladding temperature if desired.

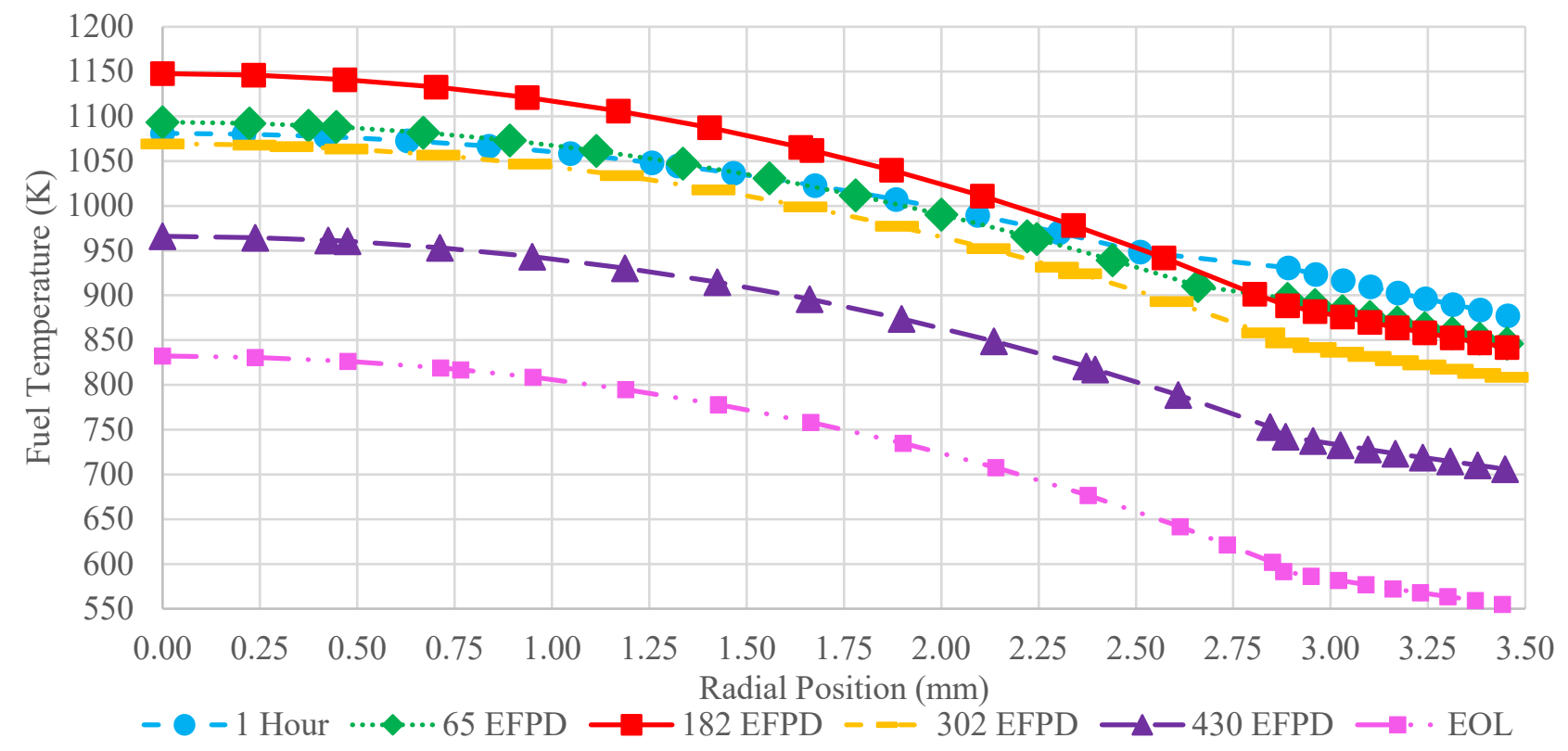

Figure 7. Radial temperature distribution of the IFR-1 BISON model throughout the pin's life cycle.

\subsection{BURNUP}

Burnup results from the BISON model compared very well against past work, within $5 \%$ relative error. The distribution (Figure 8 ) illustrates the peak of $8.7 \%$ occurring at roughly $0.42 \mathrm{~m}(\mathrm{x} / \mathrm{L}=0.5)$, as previously mentioned; this location of the peak burnup needs to be examined. 


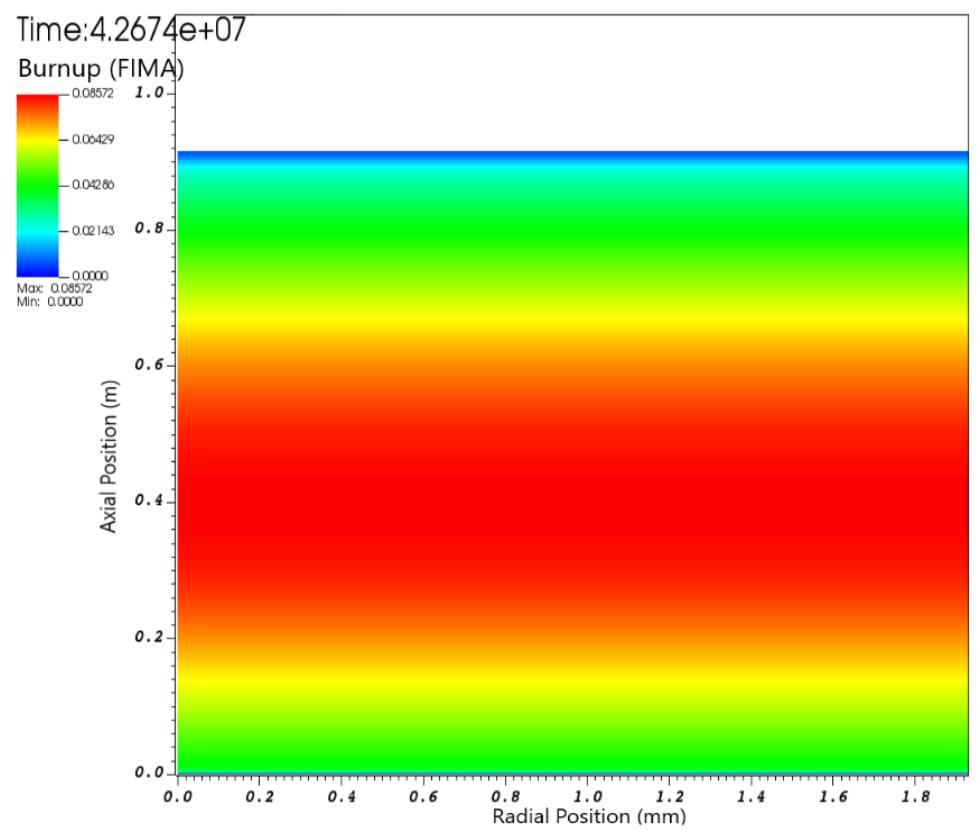

Figure 8. BISON IFR-1 model overall burnup distribution visualization generated in NEAMS Workbench's VisIt GUI. ${ }^{7}$

Relative errors were calculated for each cycle for which experimental data were available, as shown in Table 6. Given the difficulty in directly measuring burnup or indirectly inferring burnup using destructive assay to measure quantities and ratios of certain isotopes, this experiment result is in effect a previous result from neutronics calculations. Relative errors were calculated by subtracting the actual value from the simulation value and then dividing that quantity by the simulation value. The average relative error across the cycles was 2.91\%. The burnup values are also illustrated in Figure 9, further showing the small relative error.

Table 6. IFR-1 Experiment and BISON Model Burnup Results and Relative Errors

\begin{tabular}{|l|c|c|c|c|}
\hline Cycle & Time (EFPD) & $\begin{array}{c}\text { Experimental peak } \\
\text { EOL burnup } \\
\text { (\%FIMA) [4] }\end{array}$ & $\begin{array}{c}\text { BISON model peak } \\
\text { EOL burnup } \\
\text { (\%FIMA) }\end{array}$ & Relative \% error \\
\hline 9A & 138 & $2.61 \%$ & $2.67 \%$ & $2.3 \%$ \\
\hline 9B & 244 & $4.44 \%$ & $4.67 \%$ & $5.2 \%$ \\
\hline 9C & 342 & $6.12 \%$ & $6.27 \%$ & $2.4 \%$ \\
\hline 10A1 & 408 & $7.18 \%$ & $7.26 \%$ & $1.1 \%$ \\
\hline
\end{tabular}

\footnotetext{
${ }^{7}$ The cladding is not visible in this figure because burnup only occurs in the fuel region.
} 


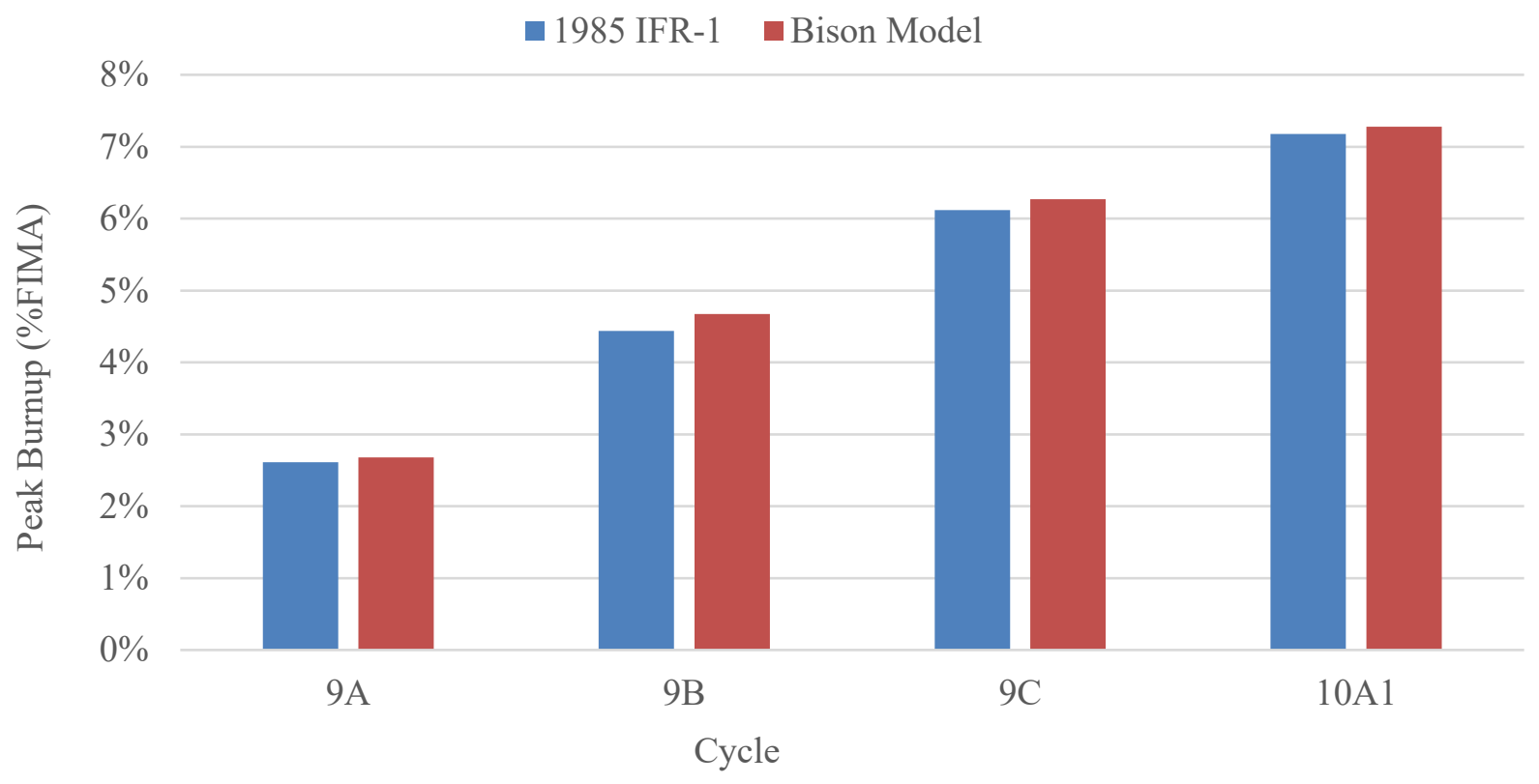

Figure 9. Comparison of burnup results between IFR-1 experiment (Porter and Tsai, 2011 [4], pp. 84-87, Appendix A) and BISON model.

\section{DISCUSSION: U-10ZR AXIAL BLANKETS}

As previously mentioned, the IFR-1 experiment contained $16.5 \mathrm{~cm} \mathrm{U}-10 \mathrm{Zr}$ axial blankets above and below the active fuel column. The reference model developed for this effort used a modeling approximation of ignoring these axial blankets, as discussed in Section 3.1.3. However, an additional variant of the IFR-1 BISON model was created to approximate the impact of including these blankets. For this BISON model, the blanket regions were added and modeled as $\mathrm{U}-19 \mathrm{Pu}-10 \mathrm{Zr}$ (the same as the active fuel), and then the axial power distribution was defined to reduce the relative power for the first and last six values to 0.1 . The height of the active fuel was extended to $124.4 \mathrm{~cm}$ to accommodate the blanket addition. These changes in the BISON input model are shown below.

\section{[Mesh]}

pellet_height $=124.4 e-02 \#$ blankets

[ ]

\section{[. /axial_peaking_factors]}

$\mathrm{x}=$ ' 0 0.000821953...0.913433187' \# axial length, 29 points

$y=' 0$ 3600...44422560' \# time in seconds, 13 points

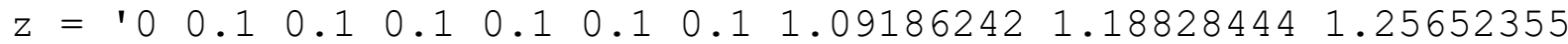

$1.296591561 .31728199 \quad 1.32221131 \quad 1.32212284 \quad 1.30407578$

$1.275456451 .22218224 \quad 1.14777528 \quad 1.05576358 \ldots 0.70926830 .10 .1$

$0.10 .10 .10 .10 .1^{\prime}$ \# relative power, $13 \times 29$ points

$[\ldots /]$

The goal of this model with the blankets included was to assess the impact of minimal power production within the top and bottom blanket portions of the fuel. This produced a significantly lower burnup percentage, reaching a maximum of $6.7 \%$ FIMA. Given the overall decreased accuracy resulting from 
approximations and the increased complexity of this model, the primary focus of this report remains the model only, including the active fuel column.

\section{CONCLUSIONS}

A two-dimensional (2D) axisymmetric model of the 1985 IFR-1 experiment performed at FFTF was successfully created and executed on a remote computational resource through the NEAMS Workbench to provide a metallic fuel analysis benchmark model in support of the VTR project using the BISON fuel performance code. Results from analysis performed using this initial model agree well with a couple burnup and temperature calculations shown in the literature that used other codes, which provides some confidence that this initial model used accurate input parameters and boundary conditions.

\subsection{FUTURE WORK}

Some areas of this model need improvement.The current IFR-1 benchmark model only includes the active fuel column. To improve the accuracy of this model, generating a more accurate model that includes axial blankets could prove useful. Current coolant parameter assumptions, particularly the incorrect inlet mass flux approximation, should also be addressed and updated to the correct FFTF values if these values can be obtained. This model would also benefit from additional capabilities in BISON, specifically material models for D9 cladding. Addressing the modeling limitations reached would not only improve this model, but would also increase BISON's versatility, thereby enhancing its usability for future metallic fuel models.

Future work should also compare results from the IFR-1 benchmark model against post-irradiation exanination (PIE) data gathered from non-detsructive or destructive analysis of the IFR-1 experiment pins. Comparisons against any in-pile measurements that can be found, in any exist, would also be beneficial.

Finally, a BISON input can contain duplicate parameters and difficult syntax constructs. An improved BISON input interface will be initiated using the NEAMS Workbench's analysis sequence processor capabilities [9] to remove duplicate input and restrictive syntax, thus enhancing usability for new users. Additionally, the new interface will automate and streamline the BISON analysis workflow. The overarching goal of this improvement will be to reduce the inclusive learning curve time typically encountered by new BISON users by simplifying input requirements through the use of templates and introducing output automation features.

\section{ACKNOWLEDGEMENTS}

The authors would like to acknowledge several people that contributed useful information and feedback. Doug Porter and Doug Crawford of the Idaho National Laboratory and Florent Heidet of Argonne National Laboratory all provided essential input parameters and operating conditions that helped model the IFR-1 experiment in BISON. Mark Baird, Paul Miller, and Brandon Langley of Oak Ridge National Laboratory provided technical assistance with computational difficulties.

Portions of this research were funded by the US DOE Office of Nuclear Energy through the VTR project and NEAMS. This research was also supported in part by an appointment to the Oak Ridge National Laboratory NESLS Program, sponsored by the US Department of Energy, and administered by the Oak Ridge Institute for Science and Education. 


\section{REFERENCES}

1. K. PASAMEHMETOGLU, "Versatile Test Reactor Overview," Idaho National Laboratory, Advanced Reactors Summit VI, San Diego, CA, USA, Jan. 29-31 (2019).

2. R.A. LEFEBVRE et al, NEAMS Workbench Status and Capabilities, ORNL/TM-2019/1314, Oak Ridge National Laboratory, September 2019.

3. R. L. WILLIAMSON et al., "Multidimensional Multiphysics Simulation of Nuclear Fuel Behavior," Journal of Nuclear Materials, 423 (2012) 149-163.

4. D. L. PORTER, H. TSAI, Full-length Metallic Fast Reactor Fuel Pin Test in FFTF (IFR-1), INL/LTD-11-21062, Idaho National Laboratory, March 2011.

5. D. L. PORTER, H. TSAI, "Full-length U-xPu-10Zr ( $\mathrm{x}=0,8,19$ wt. \%) fast reactor fuel test in FFTF," Journal of Nuclear Materials, 427 (2012) 46-57.

6. A. L. PITNER, R. B. BAKER, "Metal fuel test program in the FFTF," Journal of Nuclear Materials, 204 (1993) 124-130.

7. K. M. CUNNINGHAM, J. J. POWERS, R. A. LEFEBVRE, "Modeling the IFR-1 Metal Fuel Experiment in BISON through the NEAMS Workbench," Transactions of the American Nuclear Society, ANS Winter Meeting, Washington, D.C., Nov. 17-21 (2019), in press.

8. F. H. HUANG, "Fracture Toughness and Tensile Properties of Alloy HT9 in Thin Sections under High Neutron Fluences," Effects of Radiation on Materials: 15th International Symposium, ASTM STP 1125, R. E. Stoller, A. S. Kumar, and D. S. Gelles, Eds., American Society for Testing and Materials, Philadelphia, 1267-1286 (1992).

9. R. A. LEFEBVRE, B. R. LANGLEY, J. P. LEFEBVRE, "Workbench Analysis Sequence Processor," ORNL/TM-2017/619, Oak Ridge National Laboratory, 2017. 


\section{APPENDIX A. BISON IFR-1 INPUT FILE}





\section{APPENDIX A. BISON IFR-1 INPUT FILE}

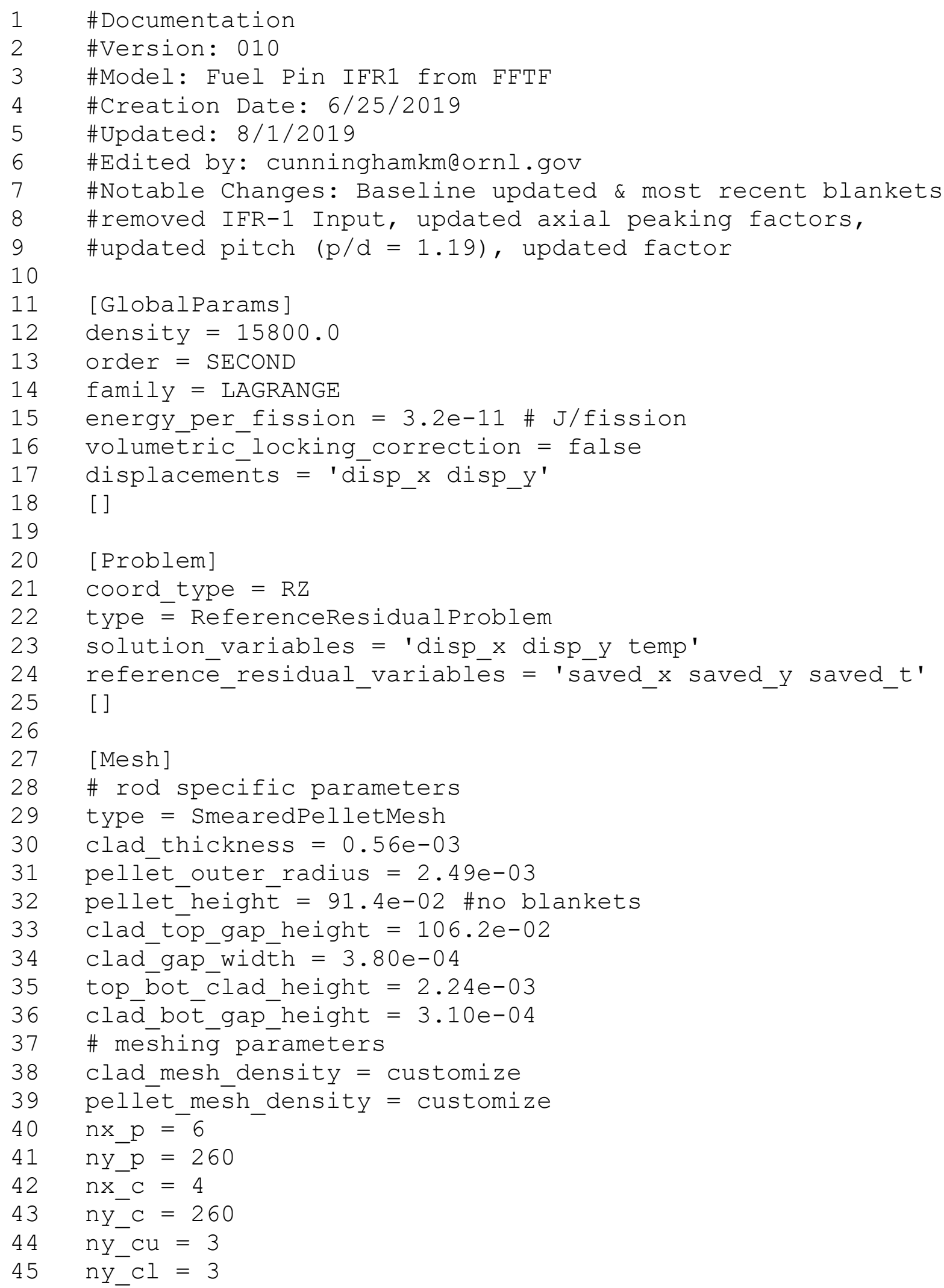




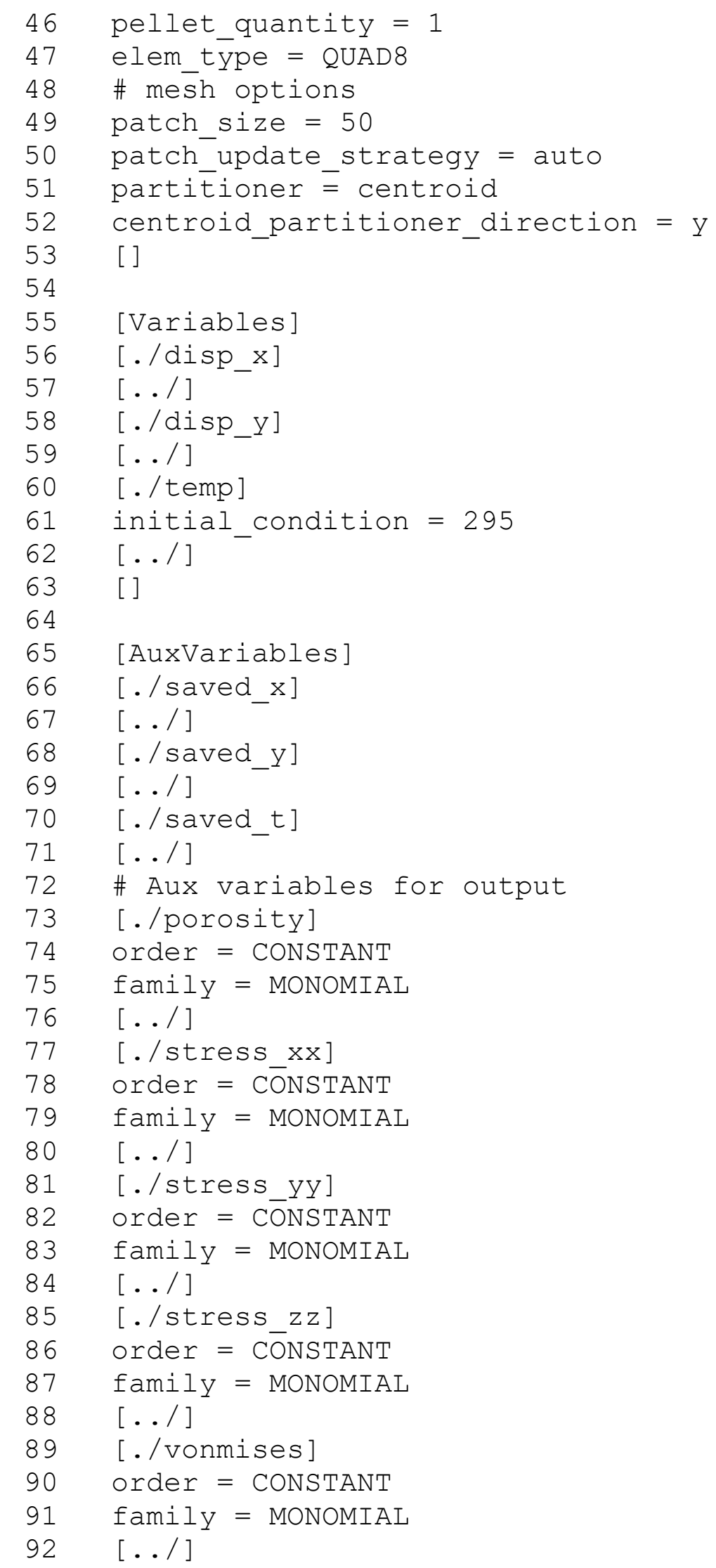




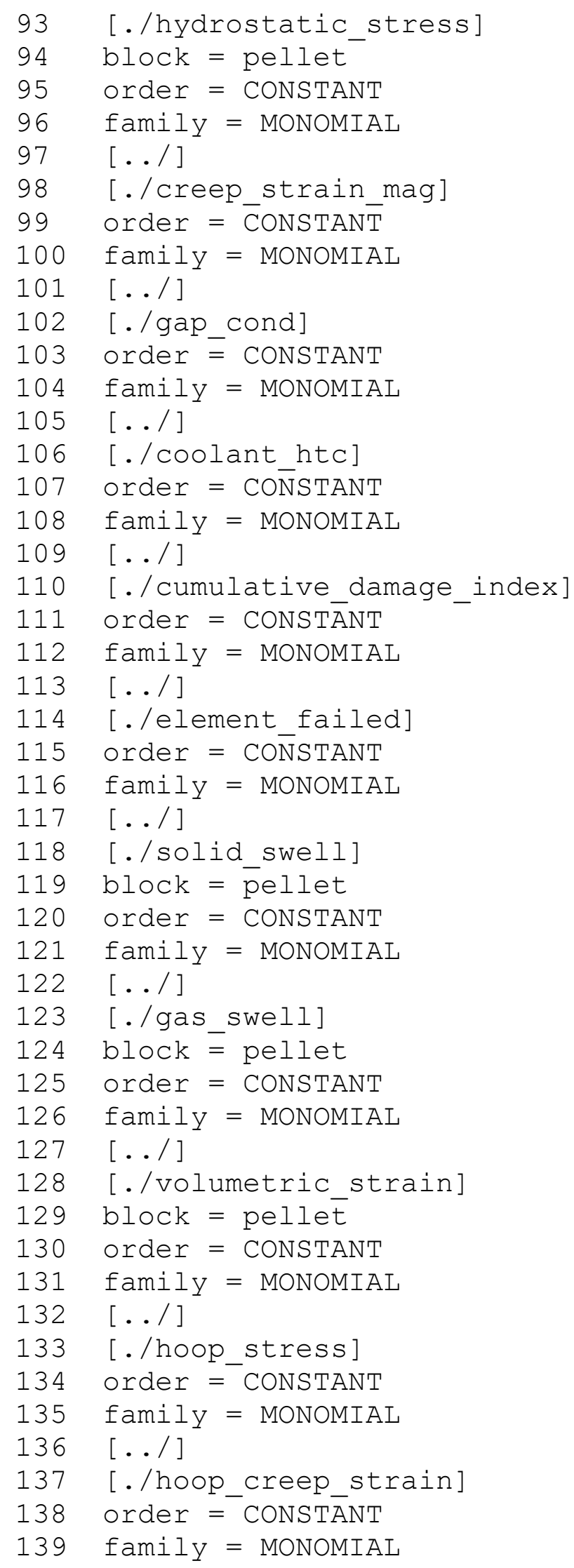




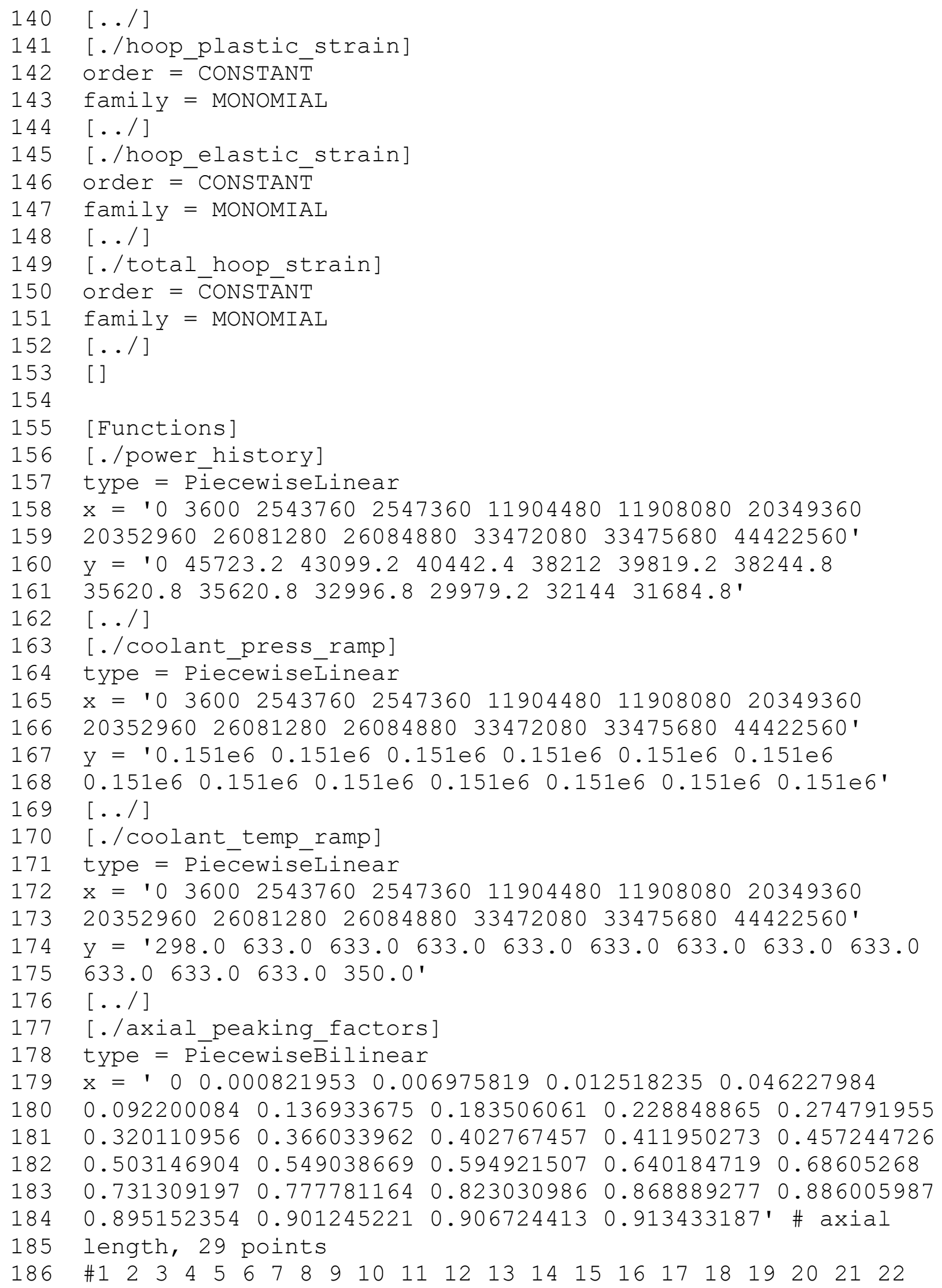


$\begin{array}{lllllll}23 & 24 & 25 & 26 & 27 & 28 & 29\end{array}$

$188 \mathrm{y}=10 \quad 360025437602547360 \quad 11904480 \quad 11908080 \quad 20349360$ $189203529602608128026084880 \quad 33472080 \quad 33475680 \quad 44422560$ ' 190 \#time in seconds, 13 points

191 Z- 29 values for $x$ listed 13 times (y)

$192 \quad z=100.49661968 \quad 0.5722864 \quad 0.64972008 \quad 0.74273203$

$\begin{array}{lllllll}193 & 0.87965259 & 0.98312476 & 1.09186242 & 1.18828444 & 1.25652355\end{array}$

$194 \quad 1.29659156 \quad 1.317281991 .32221131 \quad 1.32212284 \quad 1.30407578$

$\begin{array}{lllllll}195 & 1.27545645 & 1.22218224 & 1.14777528 & 1.05576358 & 0.94613537\end{array}$

$\begin{array}{lllllll}196 & 0.83827411 & 0.7092683 & 0.58555748 & 0.45303545 & 0.39475524\end{array}$

$\begin{array}{llllllll}197 & 0.3083747 & 0.23963428 & 0.16737763 & 0.10743662 & 0 & 0.49661968\end{array}$

$\begin{array}{llllllll}198 & 0.5722864 & 0.64972008 & 0.74273203 & 0.87965259 & 0.98312476\end{array}$

$199 \quad 1.09186242 \quad 1.18828444 \quad 1.25652355 \quad 1.29659156 \quad 1.31728199$

$200 \quad 1.32221131 \quad 1.32212284 \quad 1.30407578 \quad 1.275456451 .22218224$

$\begin{array}{lllllll}201 & 1.14777528 & 1.05576358 & 0.94613537 & 0.83827411 & 0.7092683\end{array}$

$\begin{array}{llllllll}202 & 0.58555748 & 0.45303545 & 0.39475524 & 0.3083747 & 0.23963428\end{array}$

$\begin{array}{lllllllll}203 & 0.16737763 & 0.10743662 & 0 & 0.49661968 & 0.5722864 & 0.64972008\end{array}$

$\begin{array}{llllllll}204 & 0.74273203 & 0.87965259 & 0.98312476 & 1.09186242 & 1.18828444\end{array}$

$\begin{array}{lllllll}205 & 1.25652355 & 1.29659156 & 1.31728199 & 1.32221131 & 1.32212284\end{array}$

$206 \quad 1.30407578 \quad 1.275456451 .22218224 \quad 1.14777528 \quad 1.05576358$

$\begin{array}{lllllll}207 & 0.94613537 & 0.83827411 & 0.7092683 & 0.58555748 & 0.45303545\end{array}$

$\begin{array}{llllllll}208 & 0.39475524 & 0.3083747 & 0.23963428 & 0.16737763 & 0.10743662 & 0\end{array}$

$\begin{array}{llllllll}209 & 0.49661968 & 0.5722864 & 0.64972008 & 0.74273203 & 0.87965259\end{array}$

$\begin{array}{lllllll}210 & 0.98312476 & 1.09186242 & 1.18828444 & 1.25652355 & 1.29659156\end{array}$

$\begin{array}{lllllll}211 & 1.31728199 & 1.32221131 & 1.32212284 & 1.30407578 & 1.27545645\end{array}$

$\begin{array}{llllllll}212 & 1.22218224 & 1.14777528 & 1.05576358 & 0.94613537 & 0.83827411\end{array}$

$\begin{array}{lllllll}213 & 0.7092683 & 0.58555748 & 0.45303545 & 0.39475524 & 0.3083747\end{array}$

$\begin{array}{llllllll}214 & 0.23963428 & 0.16737763 & 0.10743662 & 0 & 0.49661968 & 0.5722864\end{array}$

$\begin{array}{llllllll}215 & 0.64972008 & 0.74273203 & 0.87965259 & 0.98312476 & 1.09186242\end{array}$

$\begin{array}{lllllll}216 & 1.18828444 & 1.25652355 & 1.29659156 & 1.31728199 & 1.32221131\end{array}$

$\begin{array}{lllllll}217 & 1.32212284 & 1.30407578 & 1.27545645 & 1.22218224 & 1.14777528\end{array}$

$\begin{array}{lllllll}218 & 1.05576358 & 0.94613537 & 0.83827411 & 0.7092683 & 0.58555748\end{array}$

$\begin{array}{lllllll}219 & 0.45303545 & 0.39475524 & 0.3083747 & 0.23963428 & 0.16737763\end{array}$

$\begin{array}{lllllllll}220 & 0.10743662 & 0 & 0.49661968 & 0.5722864 & 0.64972008 & 0.74273203\end{array}$

$\begin{array}{lllllll}221 & 0.87965259 & 0.98312476 & 1.09186242 & 1.18828444 & 1.25652355\end{array}$

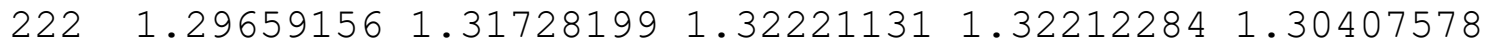

$\begin{array}{lllllll}223 & 1.27545645 & 1.22218224 & 1.14777528 & 1.05576358 & 0.94613537\end{array}$

$\begin{array}{lllllll}224 & 0.83827411 & 0.7092683 & 0.58555748 & 0.45303545 & 0.39475524\end{array}$

$\begin{array}{llllllll}225 & 0.3083747 & 0.23963428 & 0.16737763 & 0.10743662 & 0 & 0.49661968\end{array}$

$\begin{array}{lllllll}226 & 0.5722864 & 0.64972008 & 0.74273203 & 0.87965259 & 0.98312476\end{array}$

$\begin{array}{lllllll}227 & 1.09186242 & 1.18828444 & 1.25652355 & 1.29659156 & 1.31728199\end{array}$

$228 \quad 1.32221131 \quad 1.32212284 \quad 1.30407578 \quad 1.275456451 .22218224$

$\begin{array}{lllllll}229 & 1.14777528 & 1.05576358 & 0.94613537 & 0.83827411 & 0.7092683\end{array}$

$\begin{array}{lllllll}230 & 0.58555748 & 0.45303545 & 0.39475524 & 0.3083747 & 0.23963428\end{array}$

$\begin{array}{lllllllll}231 & 0.16737763 & 0.10743662 & 0 & 0.49661968 & 0.5722864 & 0.64972008\end{array}$

$\begin{array}{llllllll}232 & 0.74273203 & 0.87965259 & 0.98312476 & 1.09186242 & 1.18828444\end{array}$

$\begin{array}{lllllll}233 & 1.25652355 & 1.29659156 & 1.31728199 & 1.32221131 & 1.32212284\end{array}$ 
$234 \quad 1.30407578 \quad 1.27545645 \quad 1.22218224 \quad 1.14777528 \quad 1.05576358$

$\begin{array}{lllllll}235 & 0.94613537 & 0.83827411 & 0.7092683 & 0.58555748 & 0.45303545\end{array}$

$\begin{array}{llllllll}236 & 0.39475524 & 0.3083747 & 0.23963428 & 0.16737763 & 0.10743662 & 0\end{array}$

$\begin{array}{llllllll}237 & 0.49661968 & 0.5722864 & 0.64972008 & 0.74273203 & 0.87965259\end{array}$

$\begin{array}{lllllll}238 & 0.98312476 & 1.09186242 & 1.18828444 & 1.25652355 & 1.29659156\end{array}$

$\begin{array}{lllllll}239 & 1.31728199 & 1.32221131 & 1.32212284 & 1.30407578 & 1.27545645\end{array}$

$\begin{array}{llllllll}240 & 1.22218224 & 1.14777528 & 1.05576358 & 0.94613537 & 0.83827411\end{array}$

$\begin{array}{llllllll}241 & 0.7092683 & 0.58555748 & 0.45303545 & 0.39475524 & 0.3083747\end{array}$

$\begin{array}{lllllllll}242 & 0.23963428 & 0.16737763 & 0.10743662 & 0 & 0.49661968 & 0.5722864\end{array}$

$\begin{array}{llllllll}243 & 0.64972008 & 0.74273203 & 0.87965259 & 0.98312476 & 1.09186242\end{array}$

$\begin{array}{llllllll}244 & 1.18828444 & 1.25652355 & 1.29659156 & 1.31728199 & 1.32221131\end{array}$

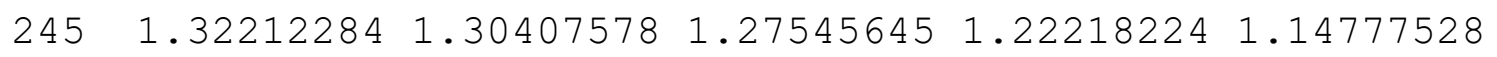

$\begin{array}{llllllll}246 & 1.05576358 & 0.94613537 & 0.83827411 & 0.7092683 & 0.58555748\end{array}$

$\begin{array}{llllllll}247 & 0.45303545 & 0.39475524 & 0.3083747 & 0.23963428 & 0.16737763\end{array}$

$\begin{array}{lllllllll}248 & 0.10743662 & 0 & 0.49661968 & 0.5722864 & 0.64972008 & 0.74273203\end{array}$

$\begin{array}{llllllll}249 & 0.87965259 & 0.98312476 & 1.09186242 & 1.18828444 & 1.25652355\end{array}$

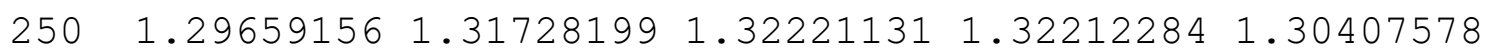

$251 \quad 1.27545645 \quad 1.22218224 \quad 1.14777528 \quad 1.05576358 \quad 0.94613537$

$\begin{array}{lllllll}252 & 0.83827411 & 0.7092683 & 0.58555748 & 0.45303545 & 0.39475524\end{array}$

$\begin{array}{lllllllll}253 & 0.3083747 & 0.23963428 & 0.16737763 & 0.10743662 & 0 & 0.49661968\end{array}$

$\begin{array}{llllllll}254 & 0.5722864 & 0.64972008 & 0.74273203 & 0.87965259 & 0.98312476\end{array}$

$\begin{array}{lllllll}255 & 1.09186242 & 1.18828444 & 1.25652355 & 1.29659156 & 1.31728199\end{array}$

$\begin{array}{lllllll}256 & 1.32221131 & 1.32212284 & 1.30407578 & 1.27545645 & 1.22218224\end{array}$

$\begin{array}{llllllll}257 & 1.14777528 & 1.05576358 & 0.94613537 & 0.83827411 & 0.7092683\end{array}$

$\begin{array}{llllllll}258 & 0.58555748 & 0.45303545 & 0.39475524 & 0.3083747 & 0.23963428\end{array}$

$\begin{array}{lllllllll}259 & 0.16737763 & 0.10743662 & 0 & 0.49661968 & 0.5722864 & 0.64972008\end{array}$

$\begin{array}{lllllll}260 & 0.74273203 & 0.87965259 & 0.98312476 & 1.09186242 & 1.18828444\end{array}$

$\begin{array}{lllllll}261 & 1.25652355 & 1.29659156 & 1.31728199 & 1.32221131 & 1.32212284\end{array}$

$\begin{array}{lllllll}262 & 1.30407578 & 1.27545645 & 1.22218224 & 1.14777528 & 1.05576358\end{array}$

$\begin{array}{llllllll}263 & 0.94613537 & 0.83827411 & 0.7092683 & 0.58555748 & 0.45303545\end{array}$

$\begin{array}{lllllllll}264 & 0.39475524 & 0.3083747 & 0.23963428 & 0.16737763 & 0.10743662^{\prime}\end{array}$

265 \# group1 group2 group3 group4 group5 group6 group7 group8

266 group9 group10 group11 group12 group 13

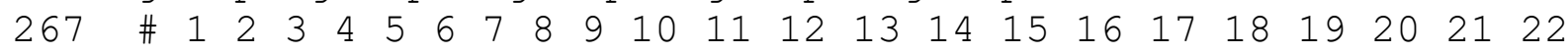

$\begin{array}{llllllll}268 & 23 & 24 & 25 & 26 & 27 & 28 & 29\end{array}$

269 axis $=1$

270 scale_factor $=1$

271

272

273

274

275

276

277

278

279

280

$[\ldots /]$

[]

[Kernels]

\# Define kernels for the various terms in the PDE system [./TensorMechanics] \#continuum mechanics stress divergence use_displaced_mesh = true \#Incremental formulation save_in = 'saved_x saved_y' $[\ldots / \overline{0}$ 


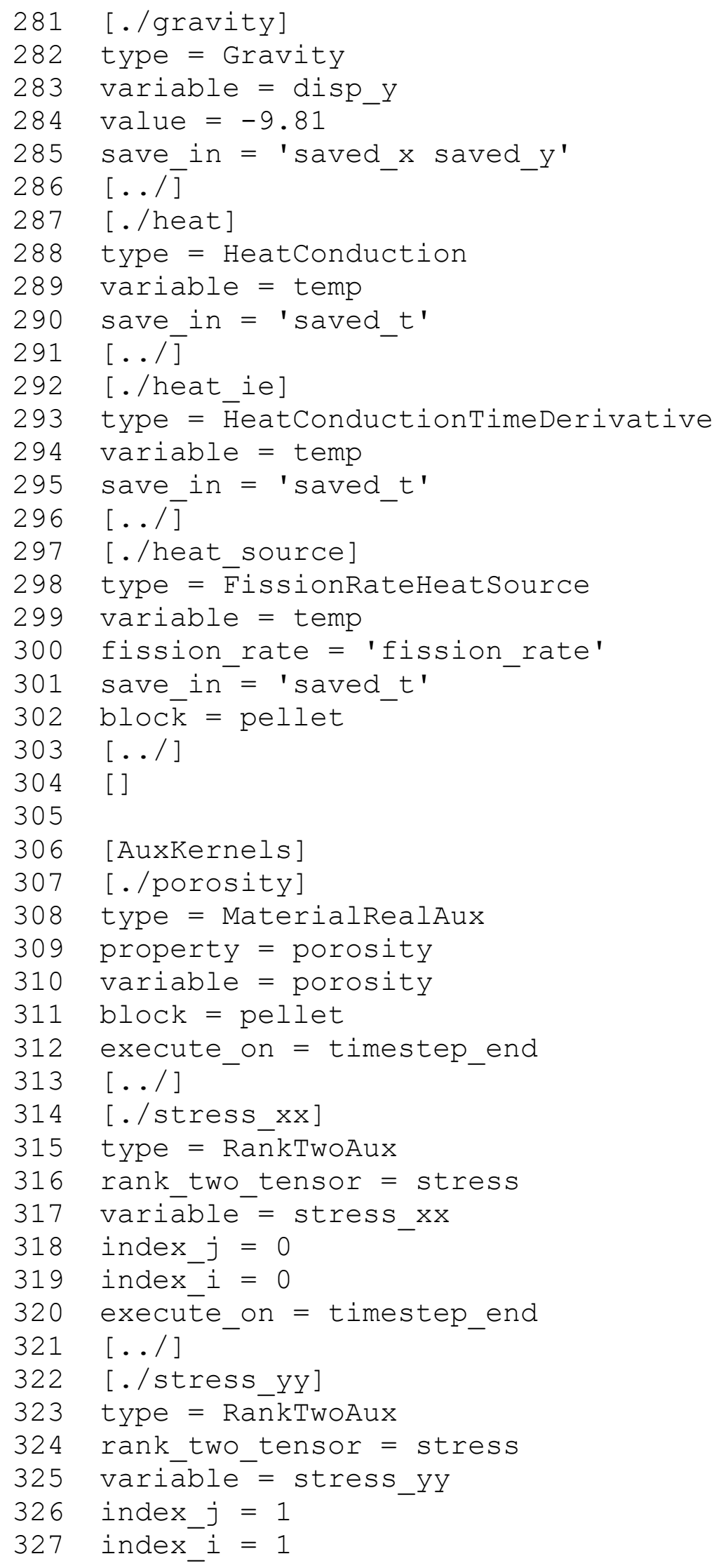




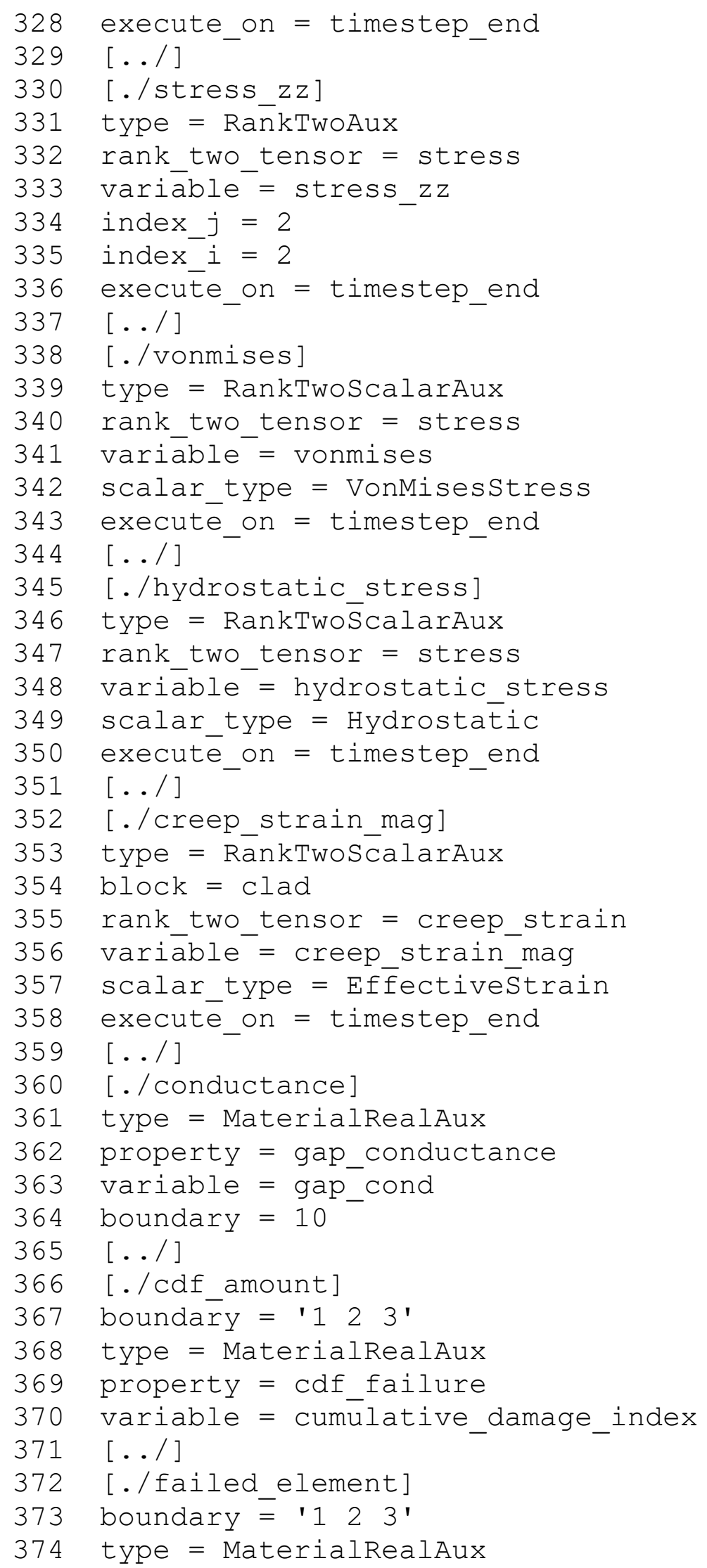




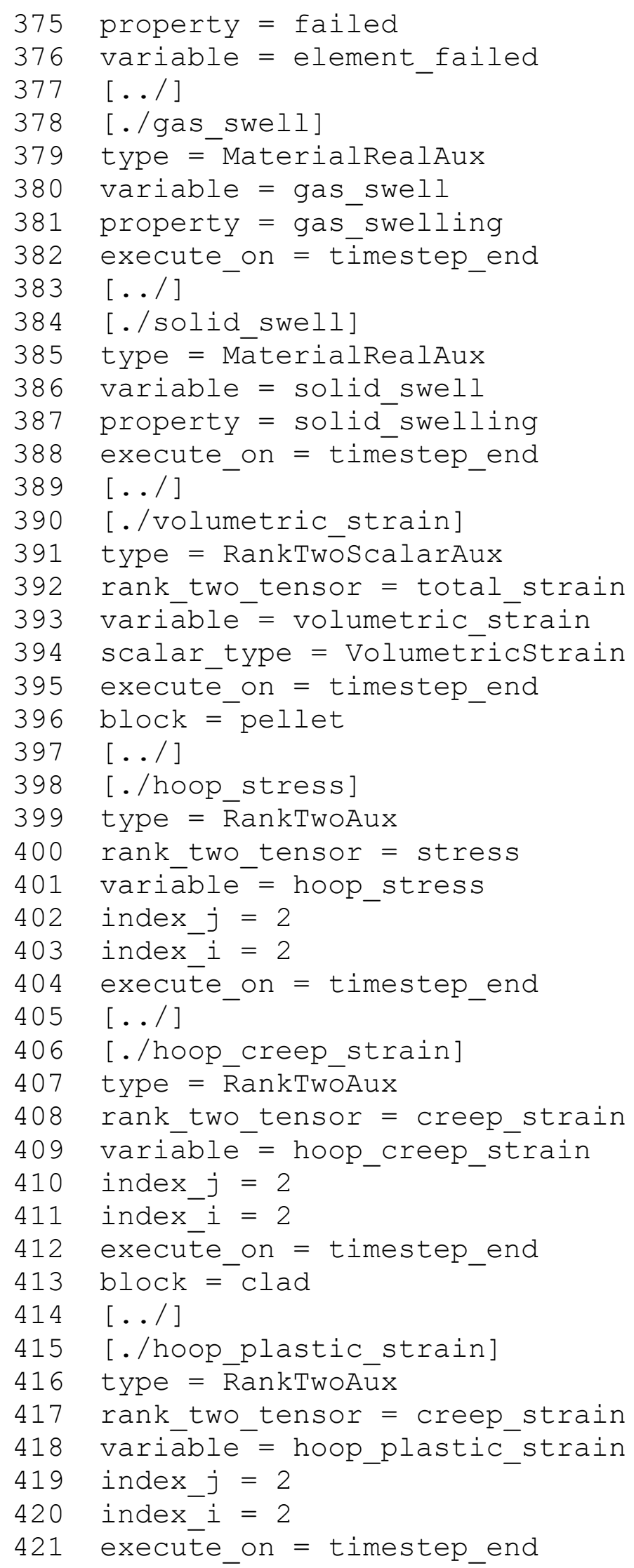




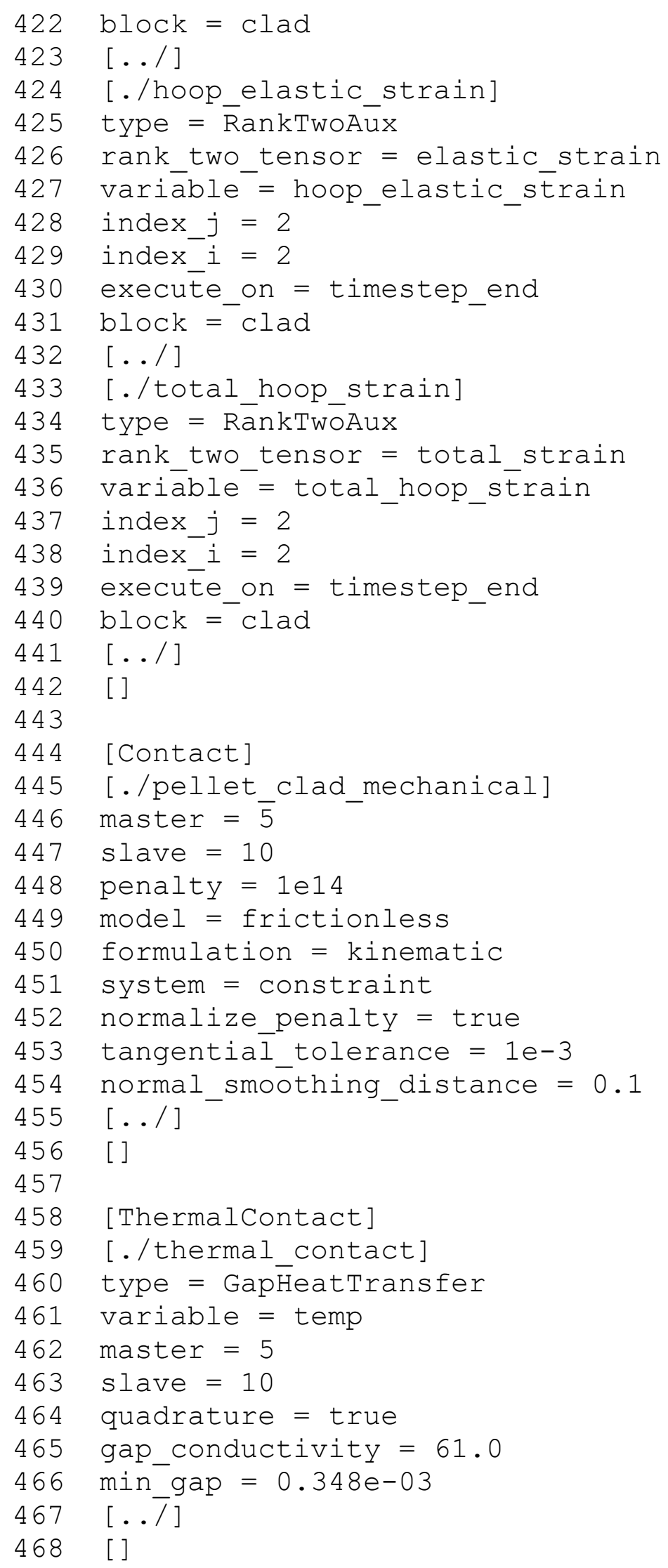


[./no_x_all]

473

type $=\bar{D}$ irichletBC

474

475

476

477

478

479

480

481

482

483

variable = disp_x

boundary $=12$

value $=0.0$

[../]

[./no_y_fuel]

type $=\bar{D}$ irichletBC

variable = disp_y

boundary $=20$

value $=0.0$

[../]

484

[./no_y_clad]

485

486

487

488

489

type $=\bar{D}$ irichletBC

variable = disp_y

boundary $=1$

value $=0.0$

[../ ]

490

[./Pressure $]$

491

[. / coolantPressure]

492

493

boundary $=$ '1 23 '

function = coolant_press_ramp

494

495

$[. . /]$

$[\ldots /]$

[./PlenumPressure]

496

497

[./plenumPressure]

498

499

500

boundary $=9$

initial_pressure $=0.084 e 6 \# \mathrm{~Pa}$

startup_time $=0$

501

$\mathrm{R}=8.3 \overline{1} 43$

502

temperature $=$ ave_temp_interior

503

504

505

506

507

508

509

volume = gas_volume

output = plenum_pressure

material_input $=$ fis_gas_released

displacements $=$ 'disp_x $\bar{d}_{\text {isp_y' }}$

$[. . /]$

$[. . /]$

[]

[CoolantChannel]

510

511

[./convective_clad_surface]

512

boundary $=11^{-} 23$ '

513

variable = temp

inlet_temperature $=$ coolant_temp_ramp

514

inlet_pressure $=$ coolant_préss_ramp

515

inlet_massflux $=5261.5 \overline{\#} \mathrm{~kg} / \mathrm{m}^{\wedge} 2-\mathrm{sec}$ 


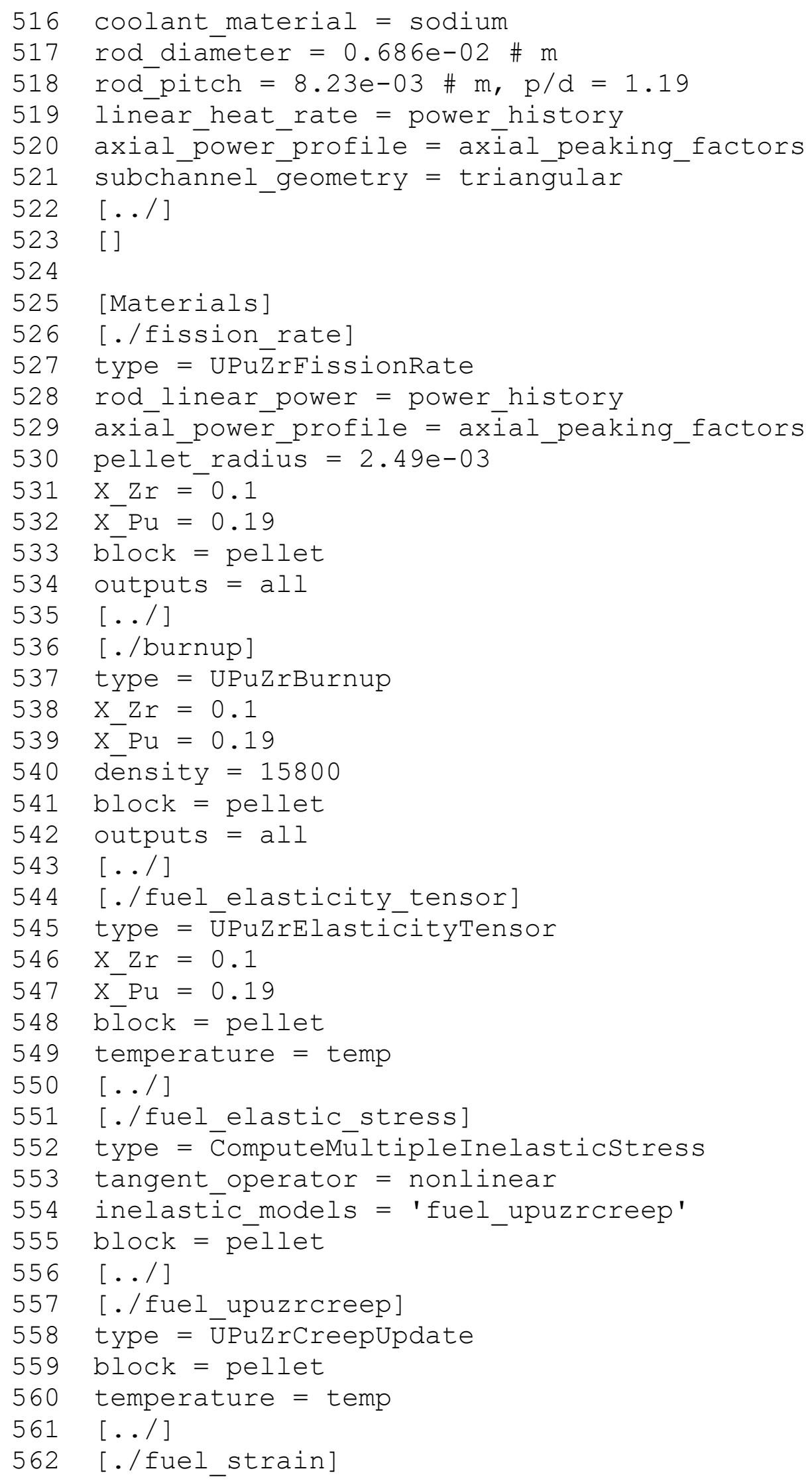




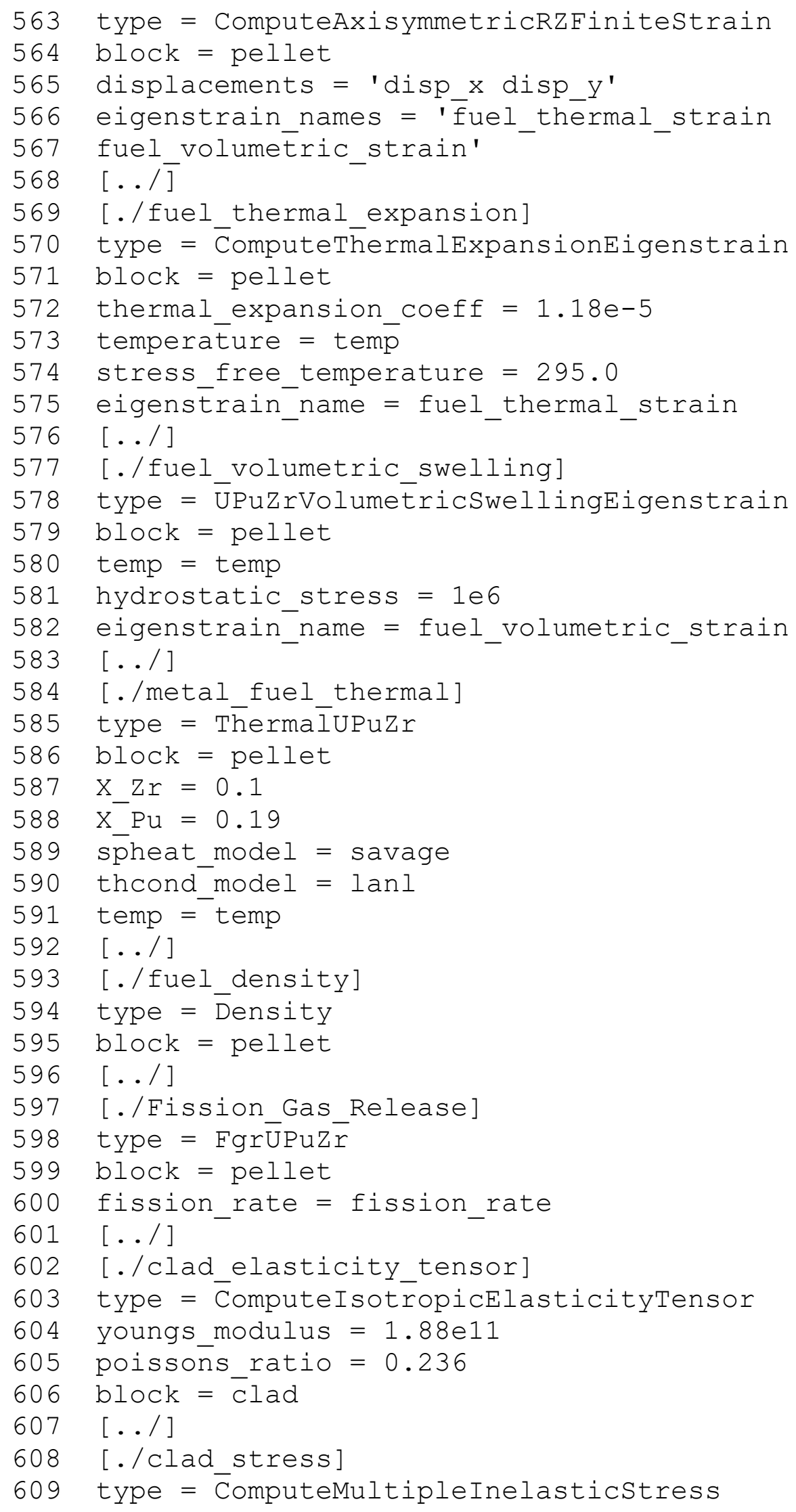




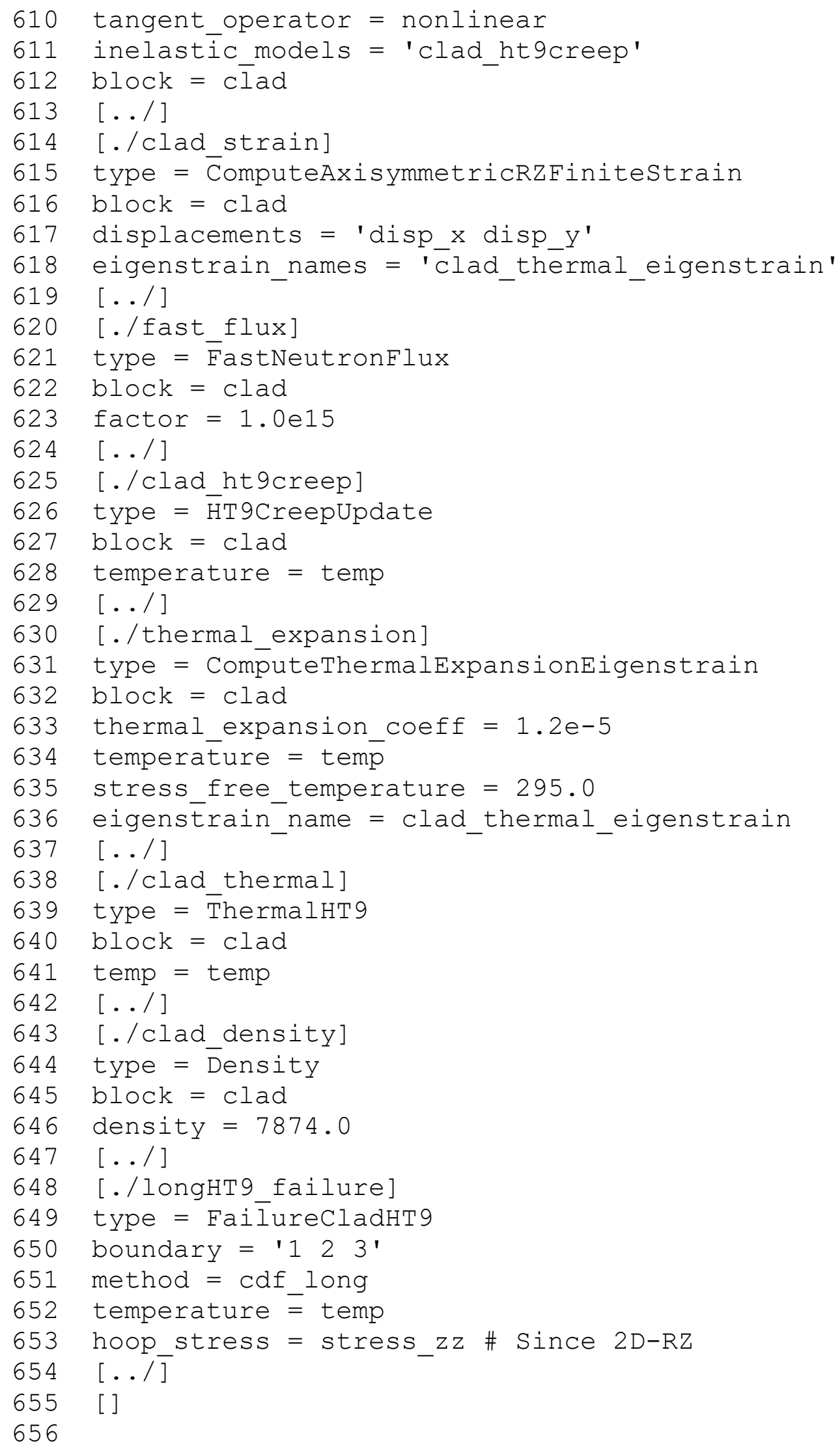




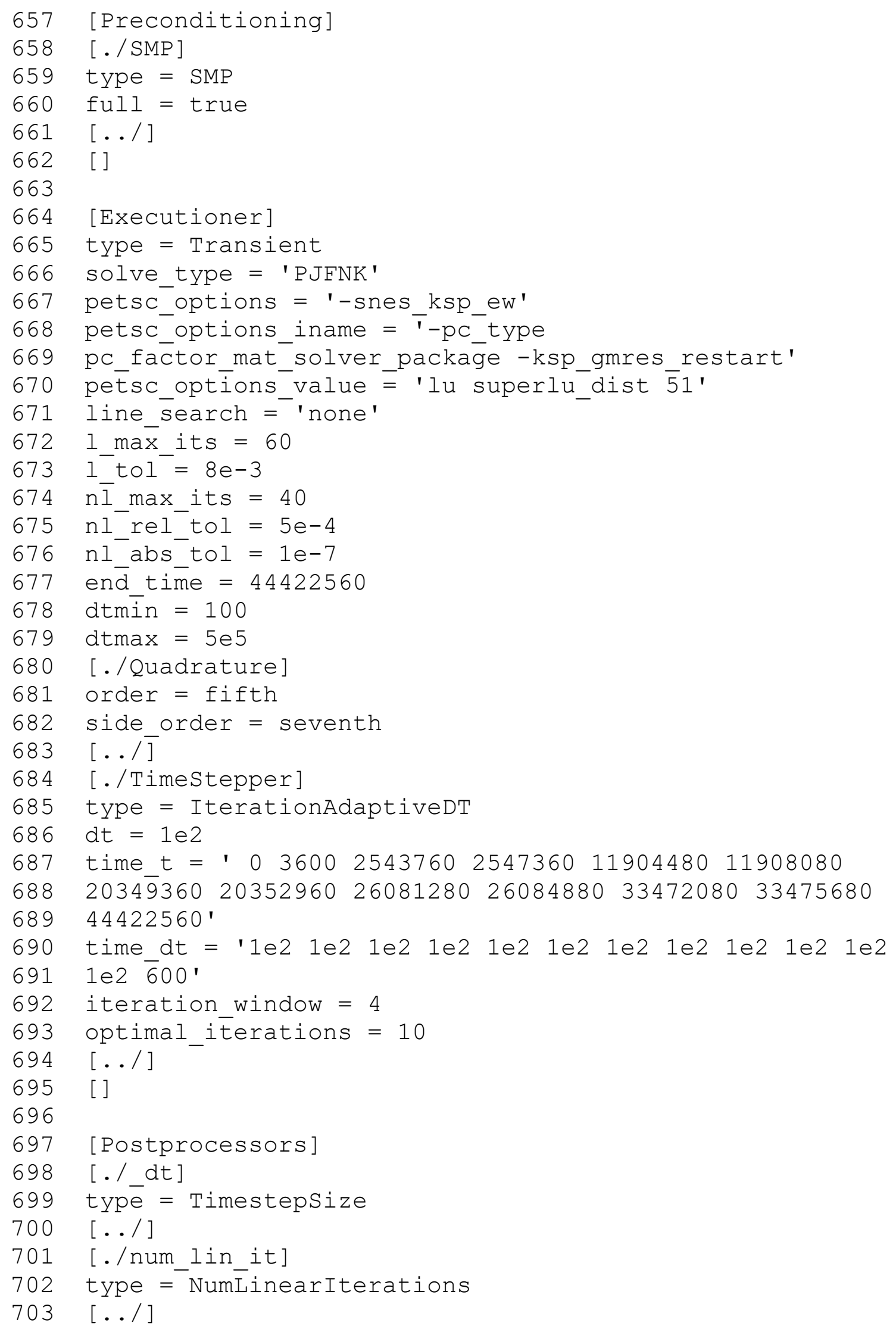




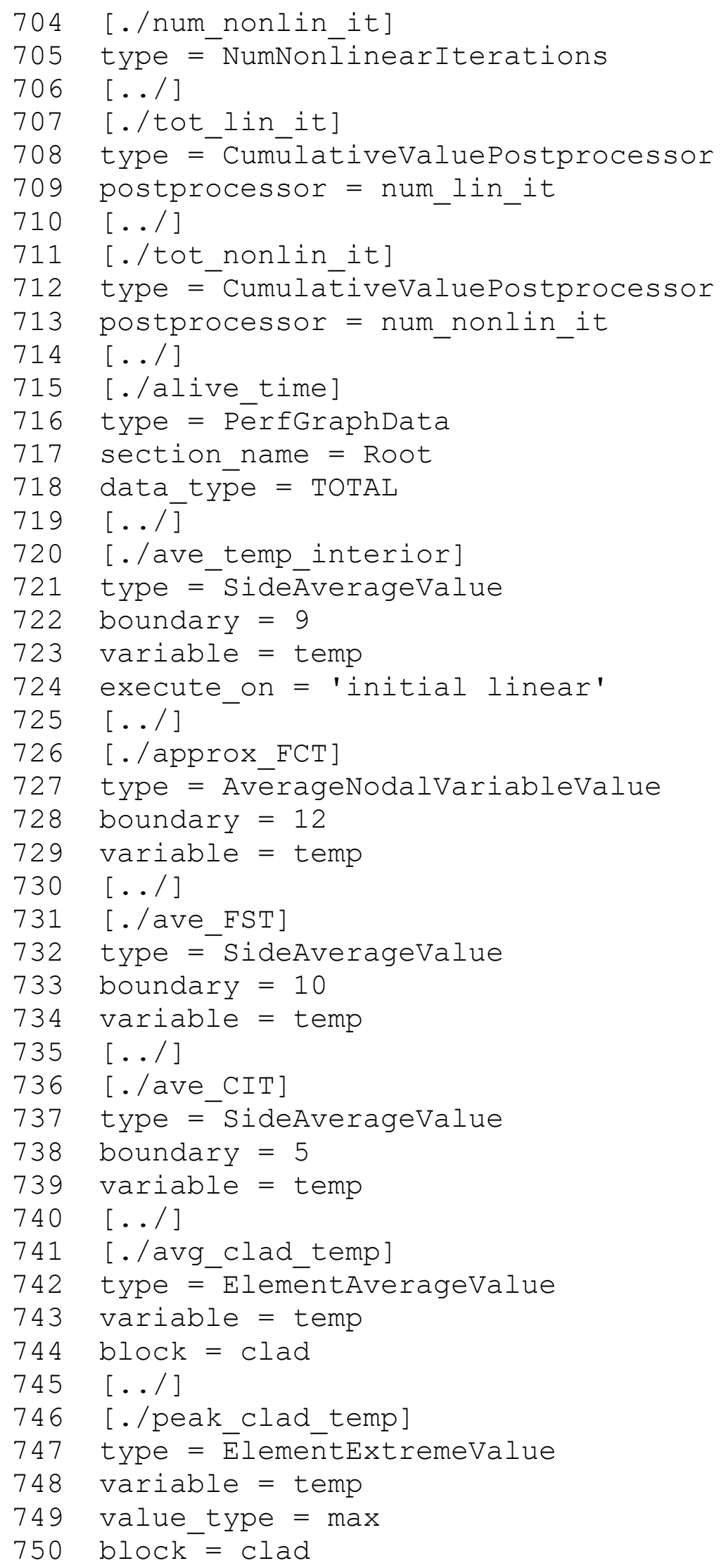




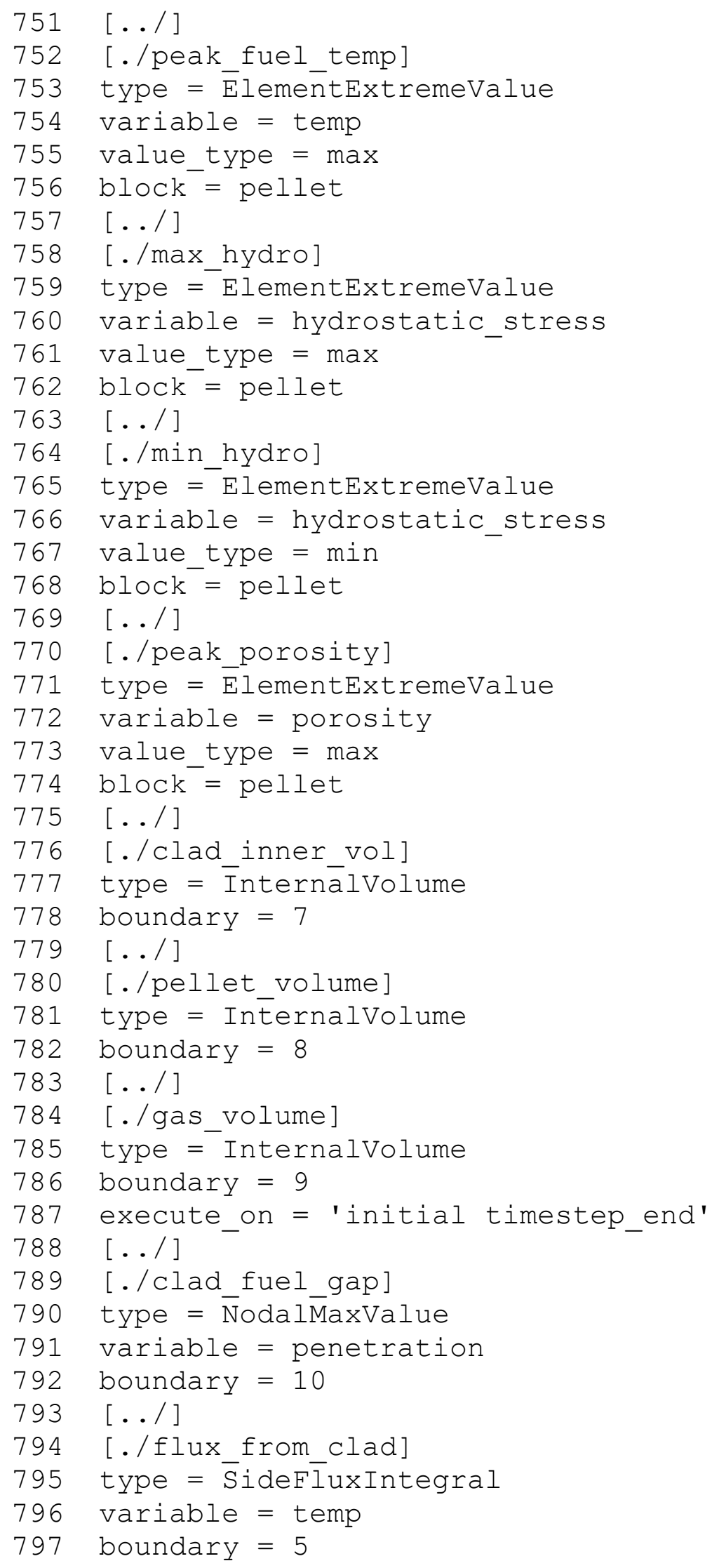




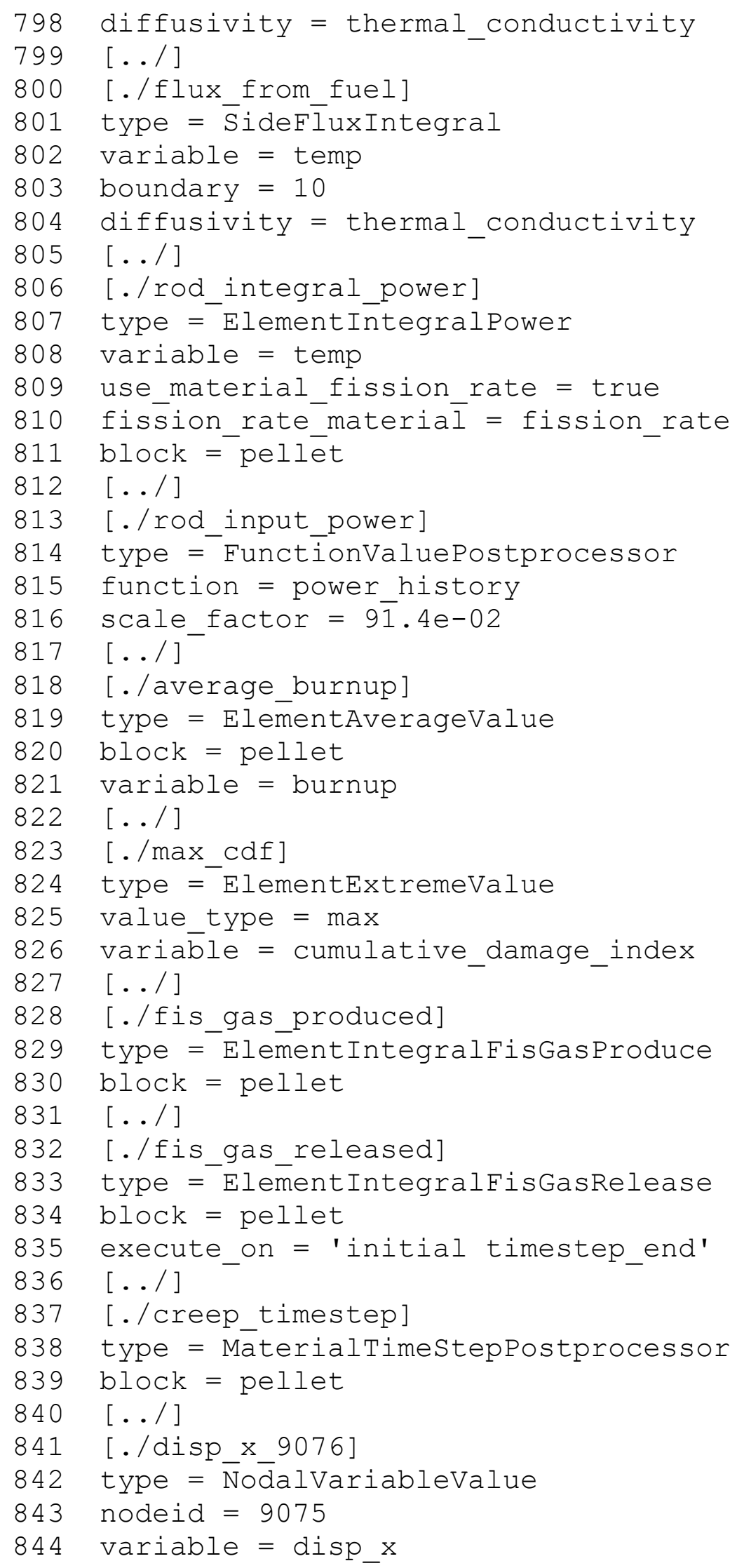




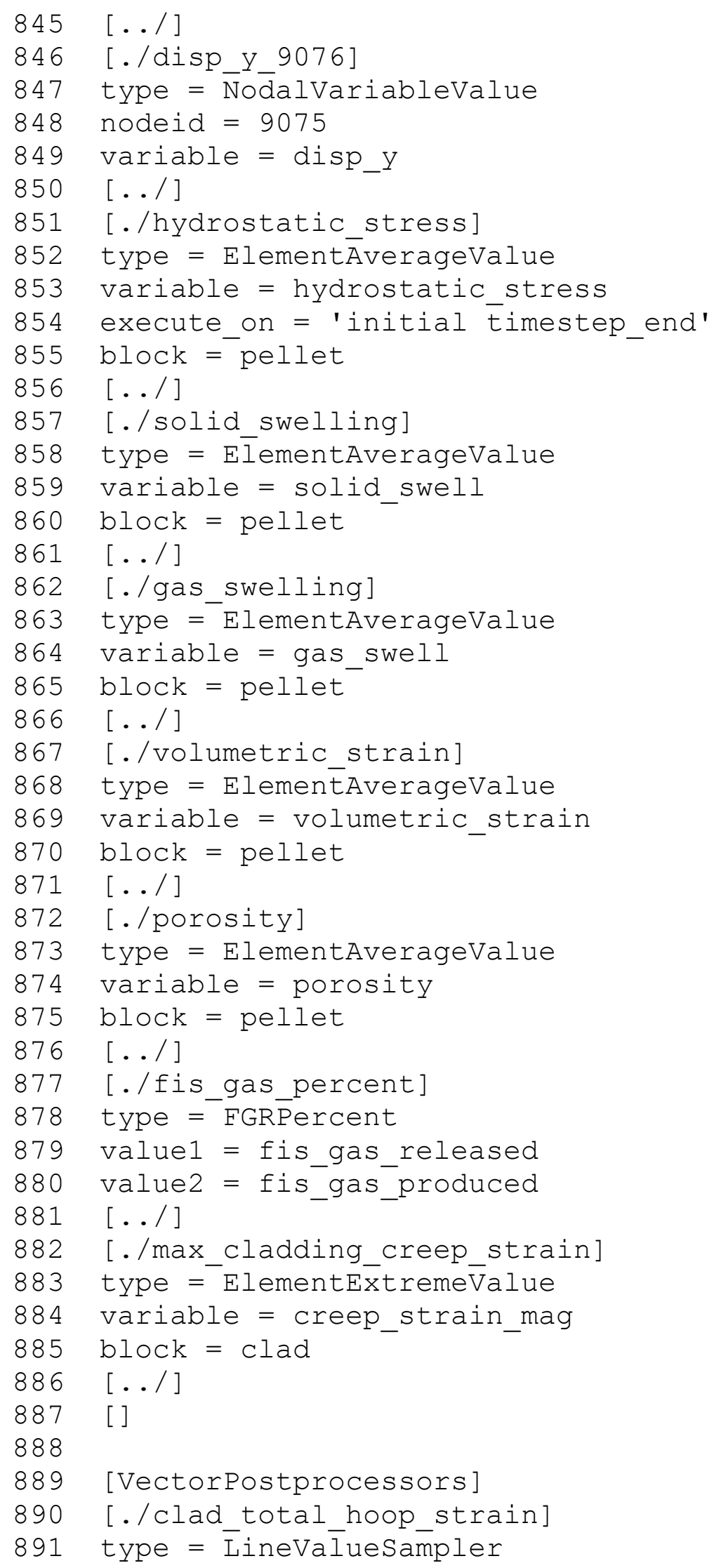




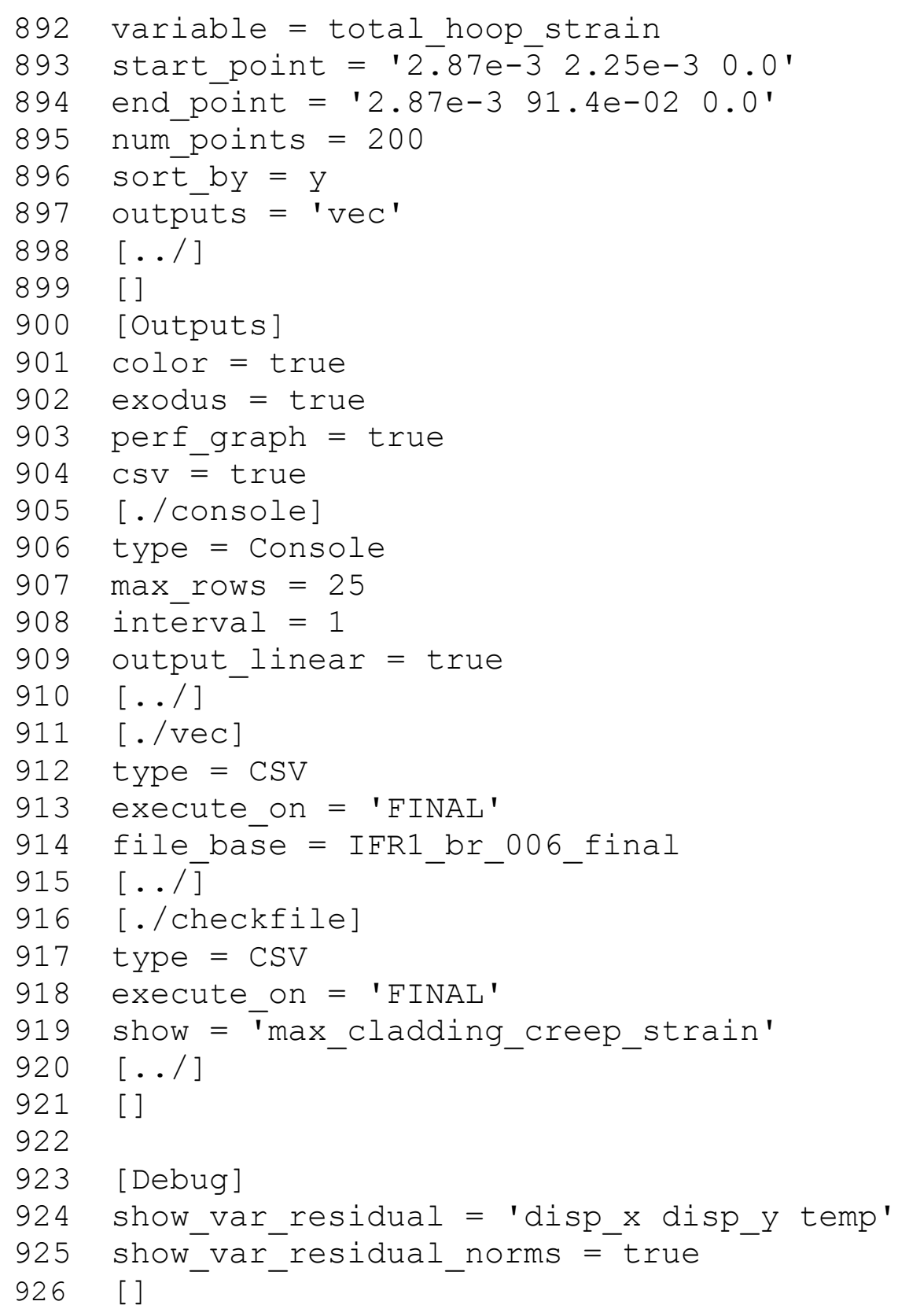

